OPEN ACCESS

Edited by:

Jan Tesarik,

MARGen Clinic, Spain

Reviewed by:

Masayuki Shimada

Hiroshima University, Japan Nalini Mahajan,

Independent Researcher,

New Delhi, India

*Correspondence:

Jesús Devesa

jesus.devesa@usc.es;

devesa.jesus@gmail.com

Specialty section: This article was submitted to Reproduction,

a section of the journal

Frontiers in Endocrinology

Received: 15 April 2019

Accepted: 21 June 2019

Published: 16 July 2019

Citation:

Devesa J and Caicedo D (2019) The Role of Growth Hormone on Ovarian

Functioning and Ovarian

Angiogenesis.

Front. Endocrinol. 10:450.

doi: 10.3389/fendo.2019.00450

\section{The Role of Growth Hormone on Ovarian Functioning and Ovarian Angiogenesis}

\author{
Jesús Devesa $^{1 *}$ and Diego Caicedo ${ }^{2}$ \\ ${ }^{1}$ Scientific Direction, Medical Center Foltra, Foundation Foltra, Teo, Spain, ${ }^{2}$ Department of Vascular Surgery, Health Research \\ Institute of Santiago de Compostela (IDIS), University Hospital of Santiago de Compostela, Santiago de Compostela, Spain
}

Although not yet well-understood, today it is clear that Growth Hormone (GH) exerts a relevant role in the regulation of ovulation and fertility; in fact, fertility is lower in women with $\mathrm{GH}$ deficiency (GHD), and $\mathrm{GH}$ receptors (GHR) and $\mathrm{GH}$ mRNA have been found in the ovary since the onset of follicular development in humans. However, despite the strong evidence of $\mathrm{GH}$ in the regulation of fertility, many aspects of $\mathrm{GH}$ actions at this level are still not well-established, and it is likely that some controversial data depend on the species analyzed, the dose of the hormone and the duration of use of $\mathrm{GH}$. Folliculogenesis, ovulation, and corpus luteum formation and maintenance are processes that are critically dependent on angiogenesis. In the ovary, new blood vessel formation facilitates oxygen, nutrients, and hormone substrate delivery, and also secures transfer of different hormones to targeted cells. Some growth factors and hormones overlap their actions in order to control the angiogenic process for fertility. However, we still know very little about the factors that play a critical role in the vascular changes that occur during folliculogenesis or luteal regression. To promote and maintain the production of VEGF-A in granulosa cells, the effects of local factors such as IGF-I and steroids are needed; that VEGF-A-inducing effect cannot be induced by luteinizing hormone (LH) or chorionic gonadotropin (CG) alone. As a result of the influences that $\mathrm{GH}$ exerts on the hypothalamic-pituitary-gonadal axis, facilitating the release of gonadotropins, and given the relationship between GH and local ovarian factors such as VEGF-A, FGF-2, IGF-1, or production of sex steroids, we assume that $\mathrm{GH}$ has to be a necessary factor in ovarian angiogenesis, as it happens in other vascular beds. In this review we will discuss the actions of $\mathrm{GH}$ in the ovary, most of them likely due to the local production of the hormone and its mediators.

Keywords: growth hormone, IGF-1, leptin, kisspeptin, GnRH, puberty, menopause, ovarian angiogenesis

\section{INTRODUCTION}

Classically, since its discovery, isolation and administration to a pituitary dwarf (1), the pituitary growth hormone $(\mathrm{GH})$ has been considered a metabolic hormone that, in addition, has specific effects on growth until puberty ends. This concept remains widely valid, despite the many and very important physiological roles that GH plays in the human body, now well-known, in virtually all tissues and organs (2). A schematic representation of these multiple functions of GH can be seen in Caicedo et al. (3), Figure 1 in this reference. Moreover, for years, we have known that apart from 
the endocrine GH expressed and released from the pituitary gland, there are expressions of the hormone in many cells and tissues, where it plays autocrine/paracrine roles (4), the meaning of which is still little understood in many cases, although its importance is beyond doubt in situations such as for example, the induction of cell proliferation or survival, or inducing the expression of glucose transporters which allow the uptake of glucose needed for the production of energy by cells. In addition, after interacting with its membrane receptor, extracellular GH is translocated to the nucleus (5), where the hormone interacts with its receptor (GHR), and its binding protein GHBP (the extracellular domain of GHR), inducing changes in transcriptional activity $(5,6)$. These findings contradicted the classical concept about the fact that protein hormones only acted on their receptors in the cell membrane. More recent studies introduce more complexity about the mechanisms of action of $\mathrm{GH}$ at the cellular level. It has been demonstrated, in pigs, that GH administration induces the translocation of GHR to cell nuclei in vivo, which may indicate that the nuclear GHR exerts functions that we do not yet know (7), although presumably, it acts there as a transcriptional factor.

In any case, the supply of GH to cells or tissues needs an adequate blood flow, and the hormone plays a very important role in the formation of new blood vessels or the recovery of damaged vasculature (3).

In the case of gonadal function in females, it seems to be of interest that, to our knowledge, the first description of the existence of a strong immunoreactivity for the GH receptor at the nuclear level, was described in 1990 in rat oocytes (8) (Figure 1). The same study found a very large distribution of the GHR/GHBP in practically all the reproductive system of the rats analyzed, suggesting that GH could play important and direct actions on reproduction, but also in the normality and integrity of the endometrial vascular system (8). Interestingly, these authors also found that this GHR/GHBP immunoreactivity was clearly higher in the ovarian granulosa cells from 10 days old rats than in granulosa cells from adult animals. This could be related to the fact that the pituitary secretion of GH gradually decreases along aging (9), but also with the fact that vasculature suffers progressive damage along life (3), with the subsequent decrease of blood supply to the ovary.

In this review, we will analyze the role played by GH for a normal ovarian function, and also the role of ovarian angiogenesis in ovarian functioning, as well as the effects of aging on both processes.

\section{OVARIAN FUNCTIONING \\ Ovarian Cycle}

The ovarian gland suffers continuous physiological and morphological changes from embryogenesis until menopause and during the physiological ovarian cycle, most of them clearly related with the intervention of $\mathrm{GH}$, apart from pituitary gonadotropins. As is logical, these changes must be accompanied by changes in the blood supply to ensure adequate supply, not only of nutrients but also of hormones and factors involved in these changes. This, in turn, means that the number, size,

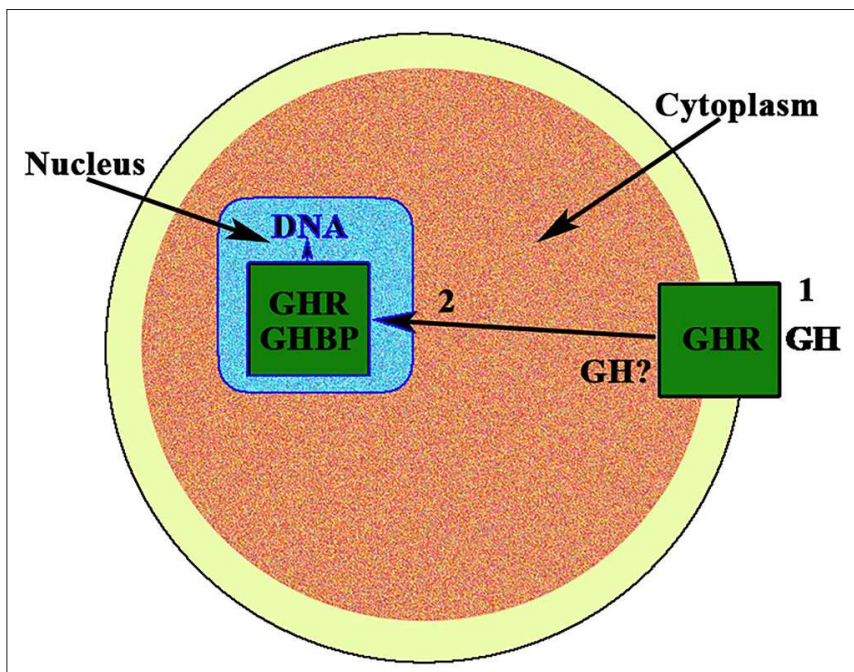

FIGURE 1 | GH receptor in the nucleus of the oocyte. In the nucleus of the oocyte, the GH receptor (GHR) and the carrier protein GHBP have been found. This means that $\mathrm{GH}$, after interacting with its membrane receptor (1), has allowed the internalization of both, GH and GHR, (2) and then the receptor is translocated to the cell nucleus where it would act as a gene transcription factor. The possibility exists that the own GH is expressed in the oocyte.

distribution, and functionality (permeability) of the blood vessels must also change considerably throughout the life of this gland, not only at the beginning of puberty but also daily, in each menstrual cycle, and during the reproductive life of a woman, until menopause. Therefore, ovarian angiogenesis is also a critically regulated process, both for ovulation and for development and function of the corpus luteum (CL).

In fact, once the puberty begins, folliculogenesis, ovulation, and $\mathrm{CL}$ formation and maintenance are processes that are critically dependent on angiogenesis. Irrigation of the ovary comes from a direct branch of the abdominal aorta, the ovarian artery, although this artery is anastomosed with a second source of ovarian irrigation, the ovarian branches of the uterine arteries, coming from the internal iliac arteries. Although these main sources of blood supply to the ovary do not change physiologically, an intricate network of preexisting, initially non-functional, arterioles and newly formed capillaries arise from them, and continually change to support the continuous changes that occur in follicular development, ovulation, luteogenesis, and luteolysis. This is in a clear contrast with that occurring in other organs and tissues, in whom, physiologically, the vascular system does not suffer significant changes (10).

In addition, the ovary is an endocrine gland from which sex steroids are released into the blood under the stimulation of pituitary gonadotropins (Gns), to perform very important functions in the female body, but also to regulate in the ovary the sequence of processes that lead to ovulation and luteogenesis. This concept is schematically represented in Figure 2.

\section{Growth Hormone and Ovarian Functioning}

As described in the Introduction, the presence of GHR in rat oocytes, and also in practically the entire reproductive system 


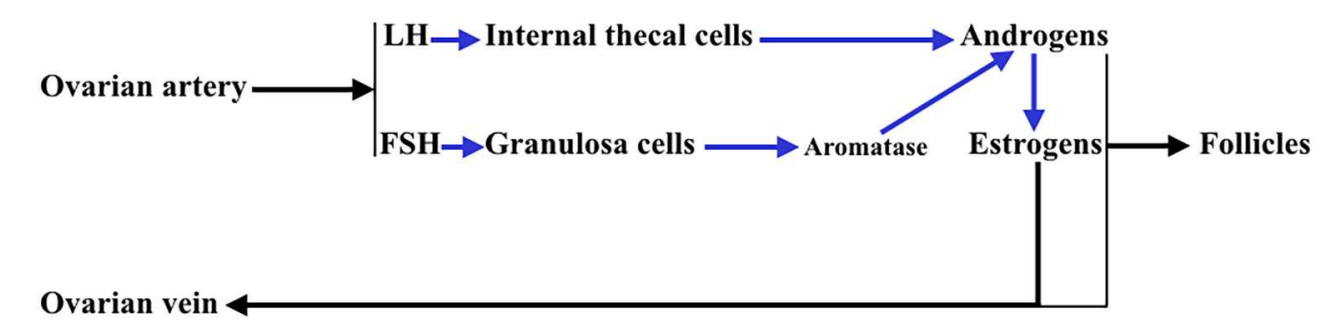

FIGURE 2 | Interactions between the theca cells of the internal layer and the granulosa cells in a growing follicle. Under the stimulus of pituitary LH, the theca cells produce androgens that reach the granulosa cells and in these, under the control of pituitary FSH, that activates aromatase, they are aromatized to estrogens (mainly estradiol). These estrogens are released into the systemic circulation and follicular fluid. Likewise, a small part of the androgens produced in the thecal cells pass into the systemic circulation.

of these animals was found almost 30 years ago (8). This was the first indication that $\mathrm{GH}$ played a very important role in the reproductive system of this species, something posteriorly verified in other animal models (11). Later studies showed that there is a genetic expression of GHR in cumulus cells, mature oocytes and preimplantation human embryos, in which there is a high expression of GHR from the 4-day morula onwards (12). This study led to the conclusion that, in humans, GH plays a role in the maturation of the oocyte and embryogenesis, from its early stages. GH and GHR have been found in human ovaries from fetuses and adults (13), where they play a very important autocrine/paracrine role.

Although most of the $\mathrm{GH}$ effects on the ovarian function are exerted by the hormone locally produced in the ovaries, systemic GH released by the pituitary gland or exogenously administered, also plays an important role in the normal function of the female gonad and reproduction, as previously reviewed by Hull and Harvey (14). Gonadal steroids participate in the hypothalamic regulation of pituitary GH secretion (9); $\mathrm{GH}$ pulse amplitude increases in hypogonadal prepubertal girls with Turner's syndrome when they receive E2 (15). In turn, GH participates in the regulation of puberty and fertility through changes in Gns secretion, directly or via IGF-1 $(16,17)$. Hypothalamic neurons producing the gonadotropinreleasing hormone $(\mathrm{GnRH})$ express IGF-1 receptors, therefore Gns secretion may be regulated, at least partially, by the GH/IGF1 axis $(16,18,19)$. IGF-1 has been shown to stimulate GnRH promoter activity in vitro $(20,21)$. IGF-1 has been found in the brain, and there its expression is stimulated by $\mathrm{GH}$, at least in human neural stem cells (22). IGF-1 is able, in rats, to stimulate the biosynthetic activity of pituitary gonadotrophs in vitro (18), and it has been shown that this peptide acts directly on $\mathrm{GnRH}$ neurons for the regulation of puberty in rats (19), although it can also act on kisspeptin neurons, which play a key role in regulating the activity of GnRH neurons [for review, see (19)]. A very recent study reveals that $\mathrm{GH}$ directly exerts effects on kisspeptin neurons located in the anteroventral periventricular and rostral periventricular nuclei via the signal transducer and activator of transcription 5 (STAT5), while the hormone lacks any effect on kisspeptin neurons located at the arcuate nucleus (23). These data agree with clinical data indicating that an appropriate secretion of $\mathrm{GH}$ is needed for sexual maturation and maintenance of reproductive functions, while GH deficiency may affect the beginning of the puberty and can produce infertility. In humans, the interaction GH-GHR in the ovary promotes the synthesis of sex steroids and induces gametogenesis, inhibits follicular apoptosis, and upregulates ovarian receptors for $\mathrm{LH}(14,24,25)$. These concepts are schematized in Figure 3. GH replacement therapy restores normal ovarian function in women with $\mathrm{GH}$ deficiency (26), in which the onset of puberty is delayed and reproductive function altered, and in infertile eugonadal women with $\mathrm{GH}$ deficiency in whom GH treatment restores fertility with successful pregnancies (27).

\section{Growth Hormone and Puberty in Females}

For years, it has been known that the onset of puberty is characterized by a change in the secretion pattern of pituitary gonadotropins. During childhood both gonadotropins circulate in low levels, and FSH secretion clearly predominates over LH secretion, whereas when puberty begins, not only do the plasma levels of both gonadotropins increase, but this pattern is also inverted. First, only during the night is the secretion of LH higher than that of FSH, and then throughout the day the menarche appears and menstrual cycles begin $(28,29)$. These pubertal changes occur as a consequence of the activation of the GnRH pulse generator, previously practically quiescent, produced by neurotransmitters acting on GnRH neurons (29) and the stimulatory effect of hypothalamic kisspeptin on them (30). The question is: why does this activation of the $\mathrm{GnRH}$ pulse generator usually occur at a certain age, highly variable among girls, during development? It is well-known that the onset of the puberty shows great changes among different ethnic populations throughout the world, which indicates that there is a genetic control on the timing of puberty (31). Although most likely the onset of puberty is polygenic, in a high number of girls a study identified the Single Nucleotide Polymorphism (SNP) rs314276 in the intron 2 of LIN28B gene, located on chromosome 6 , as the first genetic marker associated with menarche (32), although other genes also contribute to the physiology of this important event in the development $(33,34)$. Figure $4 \mathbf{A}$ shows the changes in gonadotropins and GH secretion from childhood to old age.

Besides its genetic determinant, the onset of the puberty is conditioned by the nutritional status of the individual, something 


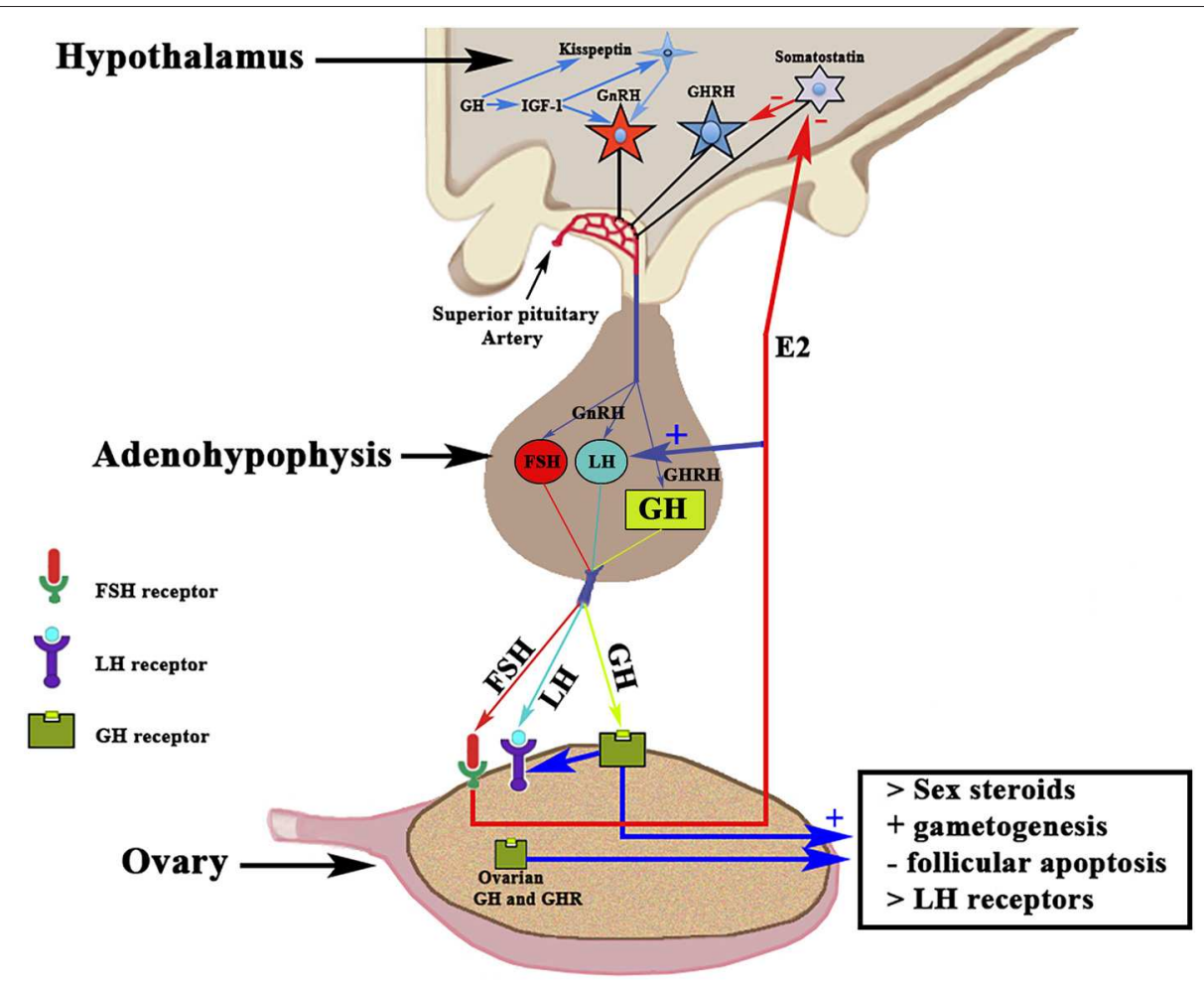

FIGURE 3 | Schematic representation of the Hypothalamic-Pituitary-Ovarian axis and the effects of GH on ovarian functioning. The activation of the GnRH pulse generator leads to the release of $\mathrm{GnRH}$ in the portal blood from which it reaches the gonadotropic cells in which it induces the release of $\mathrm{FSH}$ and LH (in proportions and amounts variable throughout a menstrual cycle) in the systemic circulation. Both gonadotropins interact with their ovarian receptors, triggering the previously described effects. The release of pituitary $\mathrm{GH}$ is induced by hypothalamic $\mathrm{GHRH}$, which is negatively regulated by somatostatin. Systemic $\mathrm{GH}$ interacts with its ovarian receptor GHR and induces the positive regulation of LH receptors. The activation of GHR induces, throughout its effects on thecal cells, an increase in the production of sex steroids, mainly estradiol (E2), which in addition to its actions at the ovarian level, is released into the general circulation. Estradiol increases the pituitary release of $\mathrm{LH}$, and also acts by inhibiting the hypothalamic release of somatostatin, which allows GHRH to be released into portal blood and stimulate pituitary synthesis and release of $\mathrm{GH}$. GH and its GHR also are produced in the ovary; therefore, the ovarian actions of $\mathrm{GH}$ may also depend on the $\mathrm{GH}-\mathrm{GHR}$ interaction. GH acts on the oocyte and the survival of the ovarian follicles. GH is also produced in the brain, where it stimulates the synthesis of IGF-1 that activates the GnRH pulse generator. In addition, both brain GH and IGF-1 stimulate kisspeptin neurons to release kisspeptin, a key factor in the activation of the GnRH pulse generator. +, stimulation; -, inhibition.

logical as a minimum availability of available energy is necessary to face the beginning of a reproductive stage. In fact, increased fat mass has been associated with precocious puberty $(35,36)$, while undernutrition or weight loss lead to delayed menarche or amenorrhea produced by hypogonadotropic hypogonadism (37). In line with this, leptin, a hormone produced by the adipose tissue (38), to regulate body fat mass by inhibiting food intake by stimulating the satiety center, is related to the onset of puberty. The reason is that increased fat mass would lead to increased leptin production, and since obesity induces precocious puberty, leptin has been considered as a metabolic signal to the reproductive system (39). More recent studies indicate that high levels of leptin in prepubertal girls are clearly associated with menarche at younger ages (40). The permissive role of leptin in the onset of puberty has been suggested to be mediated by kisspeptin neurons, given that alterations of the KISS1 gene and the kisspeptin receptor have been associated with leptindeficient production (41). Moreover, reproductive alterations can be recovered by leptin administration, both in humans and animals. Therefore, there seems to be a leptin-kisspeptin-GnRH pathway that carries metabolic information to the centers that regulate reproductive function (42). These concepts are shown in Figure 4B.

Once we have briefly analyzed how puberty starts in girls, it is appropriate to assess whether $\mathrm{GH}$ plays a role in this process. The pituitary secretion of GH increases sharply as puberty approaches; consequently, the rate of growth velocity also increases to more than double or triple the values observed throughout childhood (2). This apparent relationship between increased $\mathrm{GH}$ secretion and the onset of puberty led to the assumption that $\mathrm{GH}$ could act as a co-gonadotropin that increases the effects of FSH and LH on the production of ovarian sex steroids (43). In this line, GH-deficiency has been identified as the only cause of primary amenorrhea in three adolescent women in whom the secretion of gonadotropins was normal, suggesting that GH would play a complementary role to gonadotropins for the onset of menarche (44). As stated above, GH-deficiency negatively affects ovarian function in humans delaying sexual maturation (26) and fertility (27), a situation that is reversed with GH replacement therapy. 


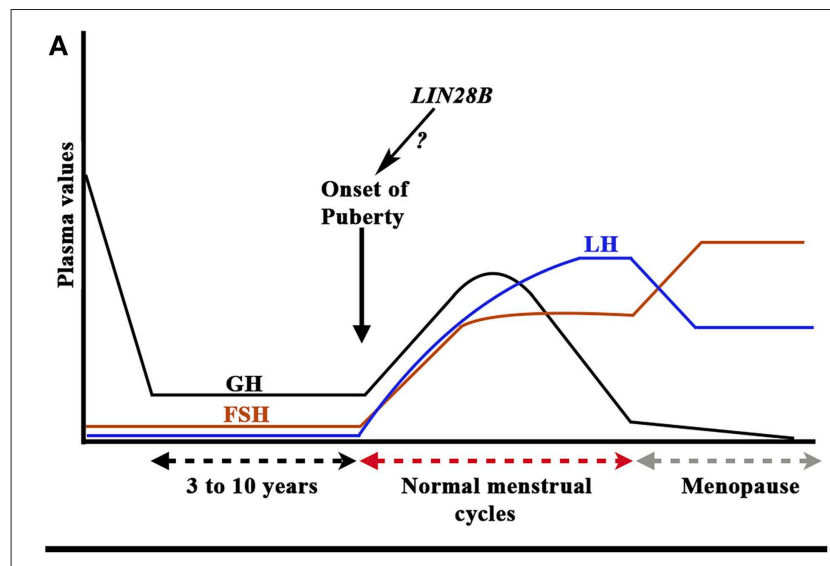

B

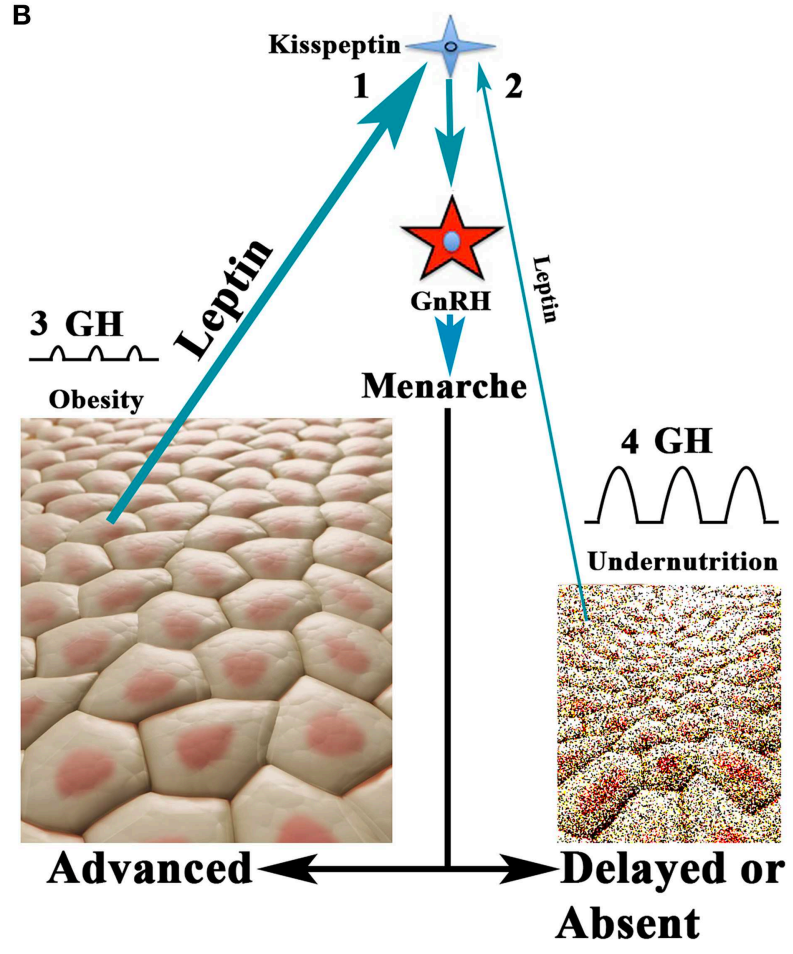

FIGURE 4 | Schematic representation of the secretion of gonadotropins and $\mathrm{GH}$ from childhood to aging, and the relationship between nutritional status and the onset of puberty. (A) Plasma GH, LH, and FSH values from childhood to aging in a normal woman. Note that during childhood the FSH levels, although low, are permanently higher than plasma levels of $\mathrm{LH}$. The onset of puberty is characterized by a nocturnal increase of $\mathrm{LH}$ on the plasma values of $\mathrm{FSH}$; then $\mathrm{LH}$ is always at higher values than that of $\mathrm{FSH}$ (with the exception of the first days of the follicular phase and the last days of the luteal phase during a menstrual cycle). At menopause, the secretion of both gonadotropins increases considerably, and the release of FSH is markedly higher than that of $\mathrm{LH}$. The evolution of the secretion of GH follows a pattern similar to that of $\mathrm{LH}$ up to $18-20$ years. From this age it decreases gradually until it is practically undetectable in old age. Curiously, the highest secretion of GH occurs when puberty begins. As shown in the figure the possibility exists that the LIN28 gene activation may be responsible for the onset of puberty. (B) There is a clear relationship between the body fat mass and the activation of the GnRH pulse generator. Adipocytes release leptin which, among other actions, stimulates the production of kisspeptin who, in turn, activates the production and secretion of $\mathrm{GnRH}$. This leads to menarche. Therefore, the greater amount of body fat, the higher secretion of leptin (1) and the lower age of onset of the

(Continued)
FIGURE 4 | puberty, while undernutrition leads to decreased leptin production (2) and this leads to delayed or absent puberty onset. In these opposite situations, the rate of secretion of $\mathrm{GH}$ does not take parallel to the onset of puberty. In obesity, the secretion of GH is considerably reduced or absent (3), whereas in girls with low fat mass the secretion of GH is markedly increased (4). This is probably due to the fact that the increase in the fat mass produces an increase in the hepatic production of IGF-1, which induces the hypothalamic release of somatostatin, but also directly inhibits the pituitary release of $\mathrm{GH}$, while undernutrition prevents the synthesis of IGF-1 in the liver, therefore leading to an increase in $\mathrm{GH}$ secretion.

It has been postulated that the increase of $\mathrm{GH}$ secretion when puberty begins depends on the activation of the GnRH pulse generator (43); the consequent increase in the secretion of LH would stimulate the production and secretion of ovarian sex steroids, which, in turn, increase noradrenergic pathways that acting on alpha-2 receptors block somatostatin secretion and allow the hypothalamic release of GHRH (9); this would lead to an increase in the synthesis and secretion of pituitary $\mathrm{GH}$ and would explain the increase in plasma levels of this hormone and the rate of growth during puberty (Figure 4A). Although this possibility is real, the fact that GH and IGF-1 stimulate, in rats, the activity of the $\mathrm{GnRH}$ promoter in vitro $(18,19)$ and kisspeptin neurons (23), may indicate that the activation of the $\mathrm{GnRH}$ pulse generator is an event that follows the increased secretion of GH/IGF-1 that occurs when pubertal maturation begins. Another possibility is that both processes occur in parallel and, physiologically, each one of them provides positive feedback to the other. It would be of interest to investigate whether $\mathrm{GH}$ might participate in the regulation of the expression of LIN28B gene or other genes involved in the onset of puberty.

As described above, the onset of puberty in girls is also dependent on the nutritional status. A recent meta-analysis indicates that obesity leads to early onset of puberty (45). This corroborates other studies that relate the increase in fat mass and early menarche $(35,36,46-50)$. However, obesity leads to a reduction or absence of GH secretion $(2,37,50)$ (Figure 4B), suggesting that $\mathrm{GH}$ does not play a role in the onset of puberty. Despite the lack of a significant secretion of $\mathrm{GH}$, although a residual secretion of the hormone in this situation cannot be discarded, the growth rate is normal or even higher in obese girls than in girls with normal fat mass (2). This can be explained by the higher levels of IGF-1 in obesity, which is the real hormone responsible for growth (2), just as early puberty in these cases can be explained by the increase in IGF-1 itself (17) and the high levels of leptin produced by the excessive fat tissue (40) (Figure 4B).

In summary, the onset of puberty in girls is a very complex process in which many factors participate. Among them, genetic factors, nutritional status, environmental factors, ethnicity, but also hormonal factors such as GH/IGF-I and leptin. GH acts in conjunction with gonadotropins and perhaps is an inducer of the activation of the $\mathrm{GnRH}$ pulse generator.

\section{Growth Hormone and Menstrual Cycles}

$\mathrm{GH}$ is a hormone that plays a very important role in the course of the processes that during a normal menstrual cycle culminate 
in the maturation and release of the oocytes; this function can be performed by the systemic hormone or the one produced in the ovary itself, but it can also depend on the ovarian IGF-1 induced by $\mathrm{GH}$, or independently produced in this gland. The attribution of a specific effect to one of these hormones or to the GH/IGF-1 system is generally difficult to be established, as most of the data on the effects of GH and IGF-1 at the ovarian level come from cultured cells or studies in animals, and the effects seem to be different depending on the species. For example, it has recently been shown in ovarian sheep cultures, that IGF-1 is present in all stages of follicular development (51). In this study, IGF-1 was found in oocytes and GCs of antral follicles, acting synergistically with FSH to stimulate oocyte growth, increasing the number of fully developed oocytes and increasing the immunoreactivity of the LH receptor in GCs (51). This effect of IGF-1 seems to be dependent on GH, at least in bovines (52). Data from studies in cultured human GCs indicate that GH stimulates the production of IGF-2, which suggest that IGF-2 may be also a mediator of GH effects in follicles acting through the receptor for IGF-1 (53).

In any case, data from studies in women indicate that the GH/IGF-1 system plays a very important role during the human menstrual cycle.

To produce a viable normal embryo, a sequence of perfectly linked processes must occur in the post-menarchal ovary. These are: steroidogenesis, folliculogenesis, oocyte maturation, and luteogenesis. After menarche, oocytes secrete a number of factors that act on the surrounding GCs to regulate the development and function of these cells $(54,55)$; this allows the primary follicles to develop into secondary follicles and then grow to the preantral and antral stages, under the control of pituitary Gns, but also $\mathrm{GH}$, as in vivo studies demonstrated that this hormone seems to be necessary for achieving an optimal maturation and survival of developing follicles $(14,56,57)$, and increases ovarian weight in some species. In contrast, the absence of effects of $\mathrm{GH}$, as occurs in knockout mice for GHR, leads to these animals to have few primary, secondary, preantral and antral follicles, and increased follicular atresia $(25,58)$.

A normal menstrual cycle begins with a predominant secretion of FSH over LH. In this situation, growing preantral follicles TCs, stimulated by LH, produce androgens, mainly androstenedione, which reach GCs where they are converted in E2 by the action of an FSH-dependent aromatase (Figure 2). Years ago it was found that in 24 normal patients, with normo-ovulatory cycles, short-term GH administration exerted a synergistic effect on the FSH-induced follicular steroidogenesis, in terms of increased E2 production during the early follicular phase, significantly higher than that induced by FSH injection without GH administration, while GH alone was unable to induce any steroidogenic response, as happened when saline was given to these women (59). This GH effect might be attributed to an action of the hormone on the activity or expression of aromatase (Figure 5A). However, it has been demonstrated that GH inhibits FSH-induced aromatase activity via an IGF-1 independent pathway, therefore inhibiting E2 synthesis in rat GCs, while, as demonstrated many years ago, IGF-1 stimulates aromatase activity (60). It has been shown that GH increases IGF-1 and its receptor, and receptors for
FSH in rat GCs via phosphorylation of Signal Transducers and Activators of Transcription (STATS), while the family of bone morphogenetic proteins (BMP) inhibits IGF-1 effects on FSHinduced $\mathrm{E} 2$ production by suppressing the expression of the ovarian GH/IGF-1 (61) (Figure 5B); curiously, the GH/IGF-1 system down-regulates the expression of BMP receptors, and GH upregulates inhibitors of BMP signaling, therefore negatively affecting BMP signaling pathways (61). Regarding P4 synthesis in GCs, it is induced by FSH and GH enhances this effect through induction of steroidogenic acute regulatory protein (StAR), cytochrome P450 and 3ß-hydroxysteroid dehydrogenase, but this is blocked by BMP (Figure 5C). Therefore, and since the expression of BMP members changes throughout a menstrual cycle, it seems that the relationship between GH/IGF-1 and BMP signal intensities, and that the type of them, plays a key role in the regulation of Gns-dependent steroidogenesis in follicles. Moreover, BMP also participate in the regulation of the hypothalamic secretion of GnRH and ovarian sensitivity to Gns (62). These effects of BMP, particularly BMP-15, have been also seen in humans $(63,64)$.

In humans, as in many other species, GH seems to play a direct role in the nuclear maturation of oocytes $(12,65)$. In human oocytes, the receptor for GH has been detected in the membrane, in cumulus cells (66) and in the nucleus in mature ovaries (13), a fact that confirms that GH has to act at this level improving nuclear maturation and the expansion of cumulus cells, as has been demonstrated in primates (67), and also improving the cytoplasmic maturation of mature oocytes (68).

Once ovulation occurred there is the need of maintaining the corpus luteum and the secretion of the needed amount of P4 from it if pregnancy occurs, until the placenta begins to produce its own P4. This allows implantation and avoids abortion. It has been shown that leptin acts synergistically with GH and IGF-1 in the luteinization of GCs, which begins before follicular disruption and ovulation (69). In this context, GH also seems to play a very important role as proliferative and antiapoptotic factor. GH together with FSH stimulates the proliferation of luteinized GCs (70) and avoids the apoptosis of these cells (Figure 6). The detection of the GHR in human luteal cells (8) supports the postulate that $\mathrm{GH}$ exerts a role in the important functions of the corpus luteum.

In addition to the important actions that the GH/IGF-1 system exerts on the ovaries, GH also facilitates the development of the most appropriate maternal environment, acting in the uterus very early in gestation. Both $\mathrm{GH}$ and its receptor are expressed in the uterus of pregnant and non-pregnant women [for review, see (2)]. GH induces uterine growth, thus facilitating implantation. In fact, pregnancy maintenance requires significant uterine hypertrophy. Clinical studies carried out in women with thin endometrium indicate that patients treated with GH developed greater endometrium thickness on day 3, higher implantation rates and greater clinical pregnancy rates than the untreated control patients (71). These effects have been attributed to the fact that the hormone, via JAK2/STAT5 pathway, promotes the proliferation of endometrial cells and increases uterine vascularization (through the regulation of VEGF-A expression); these GH actions could be mediated by the autocrine IGF-1 or 

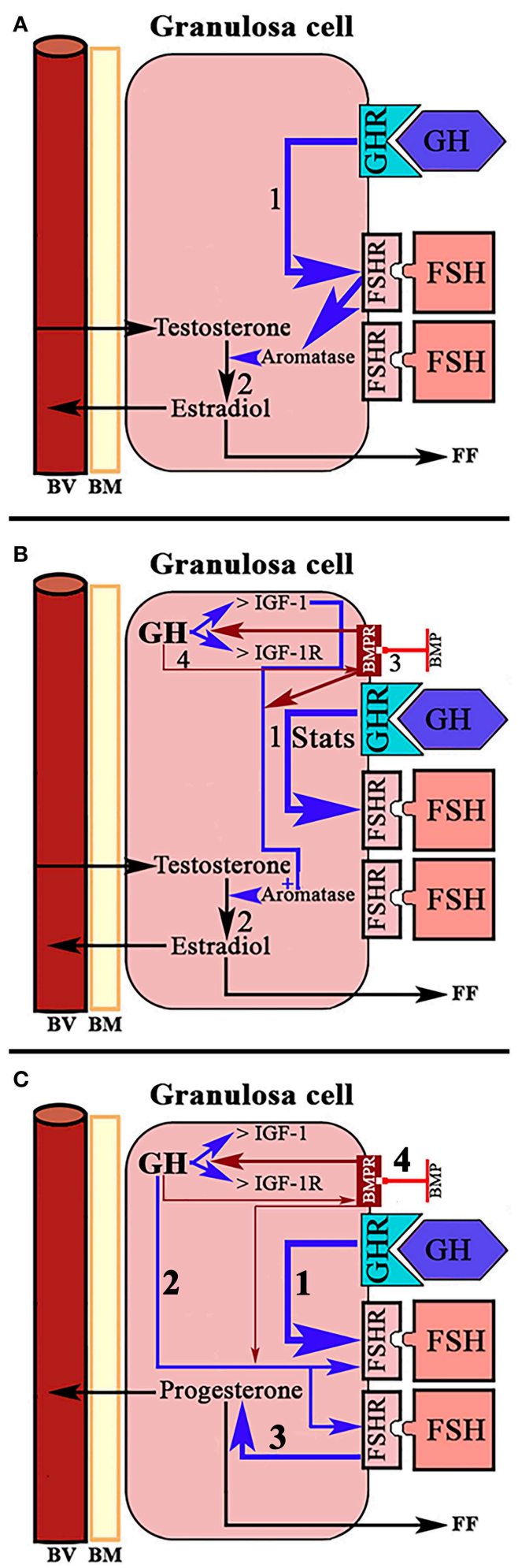

FIGURE 5 | Schematic representation of the actions of GH/IGF-1 in the ovarian granulosa cells. (A) In normal women, administration of GH in the early follicular phase exerts a synergistic effect with FSH on the production of estradiol. GH up-regulates the receptors for FSH (1) and increases the activation of aromatase by this hormone. The result is increased formation of

(Continued)
FIGURE 5 | estradiol from testosterone from the theca cells (2). (B) In rats, it has been shown that the up-regulation of FSH receptors induced by $\mathrm{GH}$ is mediated through activation of Signal Transducers and Activators of Transcription STATS (1). Ovarian GH increases the expression of IGF-1 and its receptor, and is IGF-1 which increases FSH-dependent aromatase activity (2). Bone morphogenetic proteins (BMP) suppress the expression of the ovarian $\mathrm{GH} / \mathrm{IGF}-1$ axis (3), therefore inhibiting the aromatization of testosterone to estradiol. In turn, GH/IGF-1 down-regulate the expression of BMP receptors (4). Blue arrows: stimulation. Red arrows, inhibition. (C) Systemic GH (1) and/or ovarian $\mathrm{GH}(2)$ increase progesterone production in ovarian granulosa cells induced by FSH (3), while BMP blocks this effect of GH (4). Blue arrows, stimulation; Red arrows, inhibition; BV, blood vessel; BM, basement membrane; FF, Follicular fluid.

the systemic IGF-1. As it has been described above GH facilitates implantation, most likely by increasing the production of matrix metalloproteinases and stimulating trophoblast cell proliferation which allows blastocyst cavity formation and invasion of the endometrium (72).

In summary, the GH/IGF-1 system (endocrine and autocrine or paracrine, or all of them) plays a very important function in practically all the physiological events occurring during a normal menstrual cycle, even facilitating the implantation and development of the embryo if pregnancy occurs. In this sense, we observed (unpublished data) that in six out of ten women in coma (aged between 28 and 39 years, Glasgow coma scale score $7-11$, time in coma $2-10$ years), produced by a traumatic brain injury or stroke, menstrual cycles reappeared and normalized (the patients were amenorrheic since their injury occurred), 10-18 months after beginning the administration of the hormone and rehabilitation in our Medical Center. This effect must be attributed to $\mathrm{GH}$, since it is unlikely that the rehabilitation followed may have effects at the ovarian level or on the hypothalamic-gonadotropic axis, and there are no data indicating that this could be the case.

\section{Growth Hormone and Menopause}

The pituitary secretion of GH suffers strong changes throughout human life: very high release during the first year of life, a decrease during childhood followed by a new high release when puberty begins and then a progressive decrease in the amount of hormone released in each secretory pulse [for review, see (2)]. After age 20, more or less, GH secretion is progressively declining by one-half every 7-12 years (73), and it is accompanied by a decline in plasma levels of IGF-1, although its decrease is lesser than that occurring with GH (74). Therefore, at age 50, more or less, GH secretion is residual, if it exists, and it leads to significant changes in body composition, such as reduced muscle mass, increased adiposity, reduced energy, decline in sexual activity, and increased cardiovascular risk, among other symptoms (75). Given the beneficial effects of $\mathrm{GH}$, the question is: why does $\mathrm{GH}$ secretion declines alongside aging? Deconvolution analysis of data obtained from blood sampling every 20-30 min in humans indicate that there are age-related alterations in the hypothalamic control of GH secretion, its modulation by gonadal steroids, and in GH autofeedback, leading to significantly decreased GH secretion in elder people $(76,77)$. This supports the pioneering 


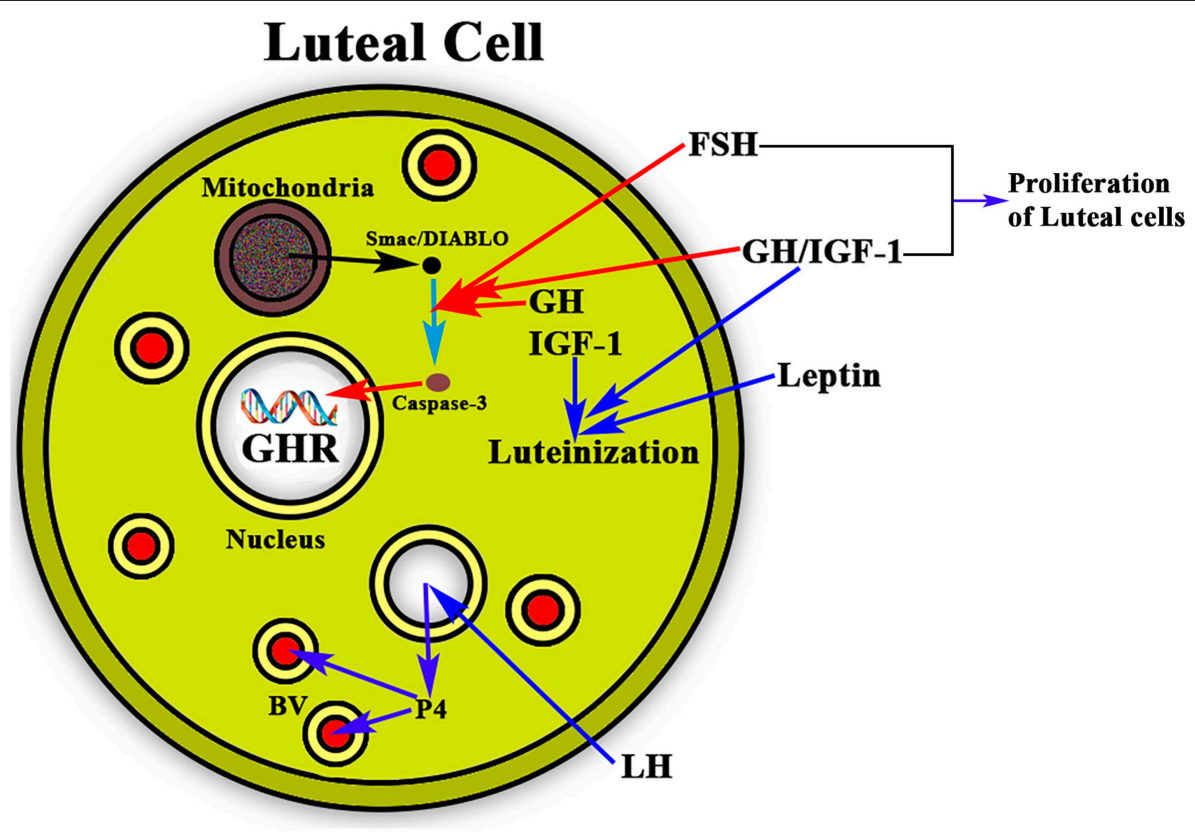

FIGURE 6 | Schematic representation of the actions of GH/IGF-1 in the ovarian corpus luteum. The figure shows a luteal cell in which the GHR can be see inside the nucleus. The production of progesterone (P4) is induced by LH, then P4 enters the bloodstream (BV; blue arrows) for playing very important functions in the body, mainly if conception exists, but also acting at many other levels, even in the brain. As shown in the figure, GH and IGF-1 are expressed in the luteal cells where they act synergistically with leptin for inducing the luteinization of the follicle that has ovulated (blue arrows). In addition, GH/IGF-1 together with FSH inhibit the possible apoptosis of the luteal cells (red arrows) by inhibiting the proapoptotic activity of caspase-3, which is stimulated by Smac/DIABLO released from the mitochondria. Moreover, GH/IGF-1 together with FSH induce the proliferation of luteal cells.

study conducted in 1985 in which it was demonstrated that the integrated concentration of $\mathrm{GH}$ during $24 \mathrm{~h}$ was strongly affected by the age of the individual (78) and also reinforces the role played by gonadal sex steroids in the neuroregulation of GH (Figure 4A).

Although GH secretion begins to decrease early in life, menstrual cycles are normally maintained until later ages (45-50 years). Menopause, the final interruption of menstrual cycling, occurs when the pool of ovarian follicles is fully depleted. This leads to a high increase in the production of Gns, with plasma FSH values that double or triple those of LH (Figure 4A). This reflects the loss of ovarian inhibit production, the main negative regulator of FSH secretion, and also the deficient production of estrogen by the menopausal ovaries, which leads to a greater release of LH. Consequently, although throughout this review, we provide a number of data showing the positive effects of $\mathrm{GH}$ in the ovaries and its role as co-gonadotropin, it seems that age-related GH deficiency is not the reason for the interruption of the normal ovarian function. In fact, the menopausal ovaries still release a small amount of E2, and the administration of $1 \mathrm{mg}$ of this estrogen twice daily during 710 days to healthy post-menopausal women induces a two-fold amplified mass of GH secreted per burst, and an augmented amplitude and mesor of the 24-h rhythm in GH release (79). The effects of E2 on GH secretion after menopause were confirmed in a double-blind, controlled study in which plasma
GH was analyzed before and after somatostatin infusion in healthy post-menopausal women treated with placebo or with an inhibitor of aromatase or a selective inhibitor of the E2 receptor. In this study a $1-\mathrm{h}$ GH peak rebound after somatostatin infusion was clearly decreased during both estrogen-deprivation protocols (80). This study concluded that GH secretion after menopause depends on low levels of ovarian estrogens, and also confirms our previous postulate about that the interruption of somatostatin release induces the synthesis and secretion of GH via GHRH (9), and that sex steroids act on GH neuroregulation by inhibiting somatostatin secretion via alpha-2 noradrenergic pathways (9).

A recent study analyzed the effects of the administration of $\mathrm{GH}$ over 26 weeks on the nocturnal pulsatile secretion of LH and the levels of sex steroids in a group of healthy postmenopausal women. Their results indicate that GH did not exert any significant effect on the secretory dynamics of LH or plasma levels of LH, nor were plasma levels of sex steroids modified, although IGF-1 did increase significantly (81). This indicates that neither GH nor IGF-1 modulates the hypothalamic-pituitarygonadal function in older post-menopausal women.

In all, these data indicate that although somatopause and menopause are more or less temporally related, once menopause begins the administration of $\mathrm{GH}$ seems to be totally ineffective at the ovarian level, likely related to the depletion of ovarian follicles while aging. 


\section{Growth Hormone and in vitro Fertilization in Poor Ovarian Responders}

Based in the data presented in this review it is likely that $\mathrm{GH}$ administration may be useful as an adjuvant therapy in in vitro fertilization (IVF) for poor ovarian responders (POR) unable to get pregnant. In fact, the combined treatment with $\mathrm{GH}$ and gonadotropins was already used many years ago with successful results in terms of more follicles developed, more oocytes collected, and higher urinary estrogens in patients with polycystic ovaries $(82,83)$. Since those studies, several different trials have been conducted combining GH treatment with Gns or human chorionic gonadotropin to induce in vitro fertility and embryo transfer in POR, and although some contradictory results have been reported, the overall conclusion is that the addition of $\mathrm{GH}$ significantly improves pregnancies in these infertile women and the number of positive results in terms of live birth rate. In this line, a recent study in 62 older women showed that cotreatment with GH led to the preovulatory down-regulation of FSHR, BMPR1B, and increased density of the largest follicles, and improved fertility in these older women in which there was already a significant decrease in the ovarian follicular reserve (84). Another study analyzed the effects of 6-week pretreatment with $\mathrm{GH}$ in POR which were submitted to an in vitro fertilization treatment. This study, carried out in 380 POR, showed that the administration of the hormone significantly improved the rate of utilization of oocytes and embryo quality increasing the live birth rates, even in older patients who had previously experienced unsuccessful results from classical techniques (85). Moreover, another recent study demonstrated that co-treatment with $\mathrm{GH}$ in patients with normal ovarian response significantly increased pregnancy rate (86). Therefore, from these and other studies, it seems to be clear that GH plays a key role in ovarian fertility and Assisted Reproductive Techniques. An extensive and detailed analysis of these effects of GH as adjuvant therapy in IVF and embryo transfer can be seen in the review carried out by Li et al. (87).

\section{OVARIAN ANGIOGENESIS}

As is logical, and it has been briefly described before, for a normal ovarian functioning the gland needs to receive an adequate and perfectly regulated blood supply.

Follicles are the main functional structures of the ovaries; they are formed during fetal development and are composed of a single layer of cells, granulosa cells (GCs), that surround the oocyte. These are the primordial, inactive follicles; these GCs are surrounded by another type of cells, the thecal cells (TCs) which will play a very important role, producing sex steroids, in the development of the follicles until their final stage which culminates in ovulation and luteogenesis.

Before the beginning of the reproductive life, a number of primordial follicles have been transformed in primary follicles. These consist in the oocyte surrounded by the pellucid zone and GCs. Around these a basal membrane separates the GCs from the TCs. In each menstrual cycle, a small number of primary follicles grows until, in general, only one of them, the dominant follicle, suffer a proteolytic process that allows the release of the ovule, while the other follicles that had initially begun to evolve together with the dominant follicle, progressively suffer a process of atresia. The question is: why does only one follicle ends the process leading to ovulation in each menstrual cycle?

For years it was believed that this was due to the different aromatase activity that transformed the testosterone produced in the TCs into estradiol (E2) in GCs (Figure 2); the greater the amount of this steroid, the greater the follicular growth capacity, a characteristic of the dominant follicle. Most likely this concept is valid, but: what determines the amount of aromatase in each follicle? Years ago, it was demonstrated that in the adult ovary the vasculature is not distributed uniformly among the ovarian follicles (10). Primordial follicles and slow-growing preantral follicles only have blood supply from vessels existing in the surrounding stroma. This implies that an adequate vascular supply is a rate-limiting step in the selection and maturation of a dominant follicle (88), while those follicles with insufficient blood supply would have limited their growth and would suffer atresia; in fact, the existence of a correlation between increasing levels of the vascular endothelial growth factor A (VEGF-A) and E2 in follicular fluid agrees with the idea that follicles with highest levels of VEGF-A will grow until reaching a preovulatory state (89) (Figure 7). As the follicular development and sex steroids production is under the control of pituitary Gns and some other growth factors, both concepts are compatible. Moreover, this reinforces the important role of angiogenesis in the ovarian function. In fact, blocking VEGF-A effects on the ovary leads to marked decrease of proliferation in the theca of secondary and tertiary follicles and also decreases GCs proliferation and the subsequent production of sex steroids.

\section{How Ovarian Angiogenesis Is Regulated?}

Fibroblast growth factor-2 (FGF-2) was the first factor identified as pro-angiogenic in the ovary $(90,91)$, being expressed in the mature follicle and corpus luteum. However, given its effects on many different cell types, it is not considered as a factor of interest in the ovarian angiogenesis. In fact, its ovarian expression shows small variations during a menstrual cycle in primates and other mammals. The same occurs with many other pro-angiogenic factors which are not specific of vascular endothelial cells (3).

As stated above, follicular development implies the proliferation and differentiation of GCs; the same occurs with the surrounding TCs. These processes are induced by pituitary Gns, and continue until the dominant follicle, after a sudden and high luteinizing hormone (LH) surge, releases the mature ovule and CL is formed and maturates producing mainly progesterone $\left(\mathrm{P}_{4}\right)$. If there is no conception, this CL undergoes important morphological and functional changes that lead to its regression and formation of a residual structure, as is the corpus albicans (90), in which degeneration of the vasculature exists (88). This succession of events in a menstrual cycle occurs in parallel with rapid and continuous changes in the irrigation and functionality of the ovarian structures involved (92). In fact, in the CL there is a high density of capillaries (Figure 7), as they are microvascular endothelial cells the most abundant cell type in this structure; even more so, each luteal cell is in contact with 


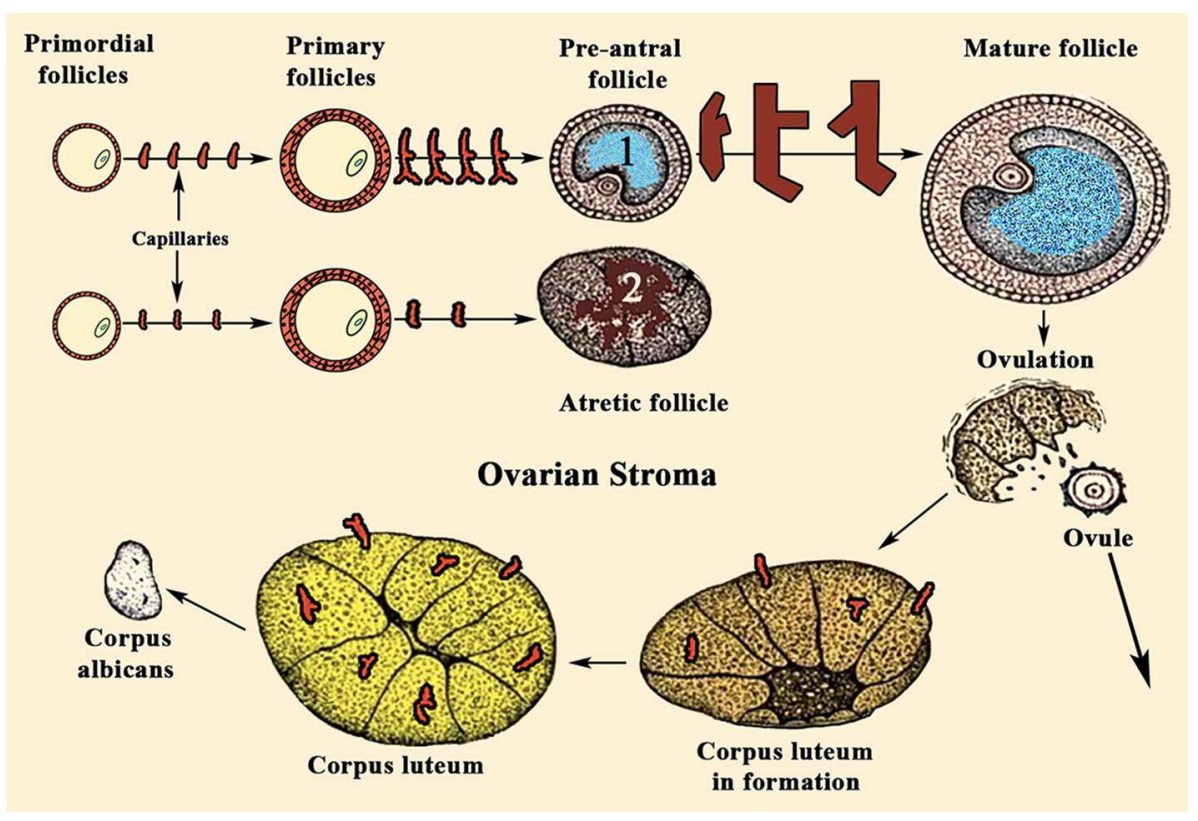

FIGURE 7 | Sequence of ovarian events during a normal menstrual cycle. During a normal menstrual cycle some primordial follicles begin to grow but, usually, only one of them reach the final maturation until it releases the ovule. It depends on the amount of VEGF-A and E2 existing in the follicular fluid. (1) Shows a dominant follicle, in which VEGF-A and E2 levels are quite higher than in the follicles that began to grow with it. These follicles degenerate and become atretic (2). Note the high number of capillaries supplying blood to follicle (1), while the atretic follicle (2) is almost privated of blood supply. VEGF-A, among other factors, is the main responsible for the generation of new small vessels supplying blood to the follicles. Similarly, after ovulation, the formation of the corpus luteum requires an increase in blood supply, as can be seen in the figure.

one capillary $(92,93)$, most likely to increase the production of $\mathrm{P}_{4}$, key for the beginning of pregnancy.

The first factor identified as main responsible of the vascular changes occurring during a menstrual cycle was VEGF-A (94). In the pre-ovulatory follicle, the granulosa layer is avascular, while the theca is strongly vascularized. During follicular development VEGF-A is accumulated, until LH induces proteolytic activity and the basement membrane is degraded; this leads to the release of VEGF-A which induces migration of endothelial cells to GCs, endothelial proliferation and sprouting of pre-existing vasculature, tube formation and recruitment of pericytes, as well as, perhaps in conjunction with other angiogenic factors, vessel stabilization, and maturation (95). These actions of VEGF-A are mediated by the VEGF-A receptor 2 (VEGF-AR2), while VEGF-AR1 seems to play a negative role suppressing signaling through VEGF-AR2.

Another group of endothelial-specific factors detected in the ovary are Angiopoietins (Ang) $(96,97)$, of which Ang2 seems to act, in the absence of VEGF-A, as an inducer of ovarian vessels destruction. This effect is produced by the binding of Ang2 to the Ang1 receptor Tie2, therefore impeding the binding of Ang1. Thus, Ang2 acts in an opposite manner than the isoform Ang1 who, like VEGF-A, is essential for normal vasculature development (97), and stabilization of newly formed blood vessels. However, in the presence of VEGFA increased autocrine expression of Ang2 by the vascular endothelium induces angiogenesis. Perhaps these divergences explain the reason by which Ang1 and Ang2 are differentially expressed in the ovary during a normal menstrual cycle. Interestingly, pituitary gonadotropins, in particuar LH, have been demonstrated to be major inducers of angiogenesis and VEGF-A/Ang expression in the ovary. The midcycle surge of LH strongly stimulates VEGF-A and Ang expression in GCs in many species, including primates (98) (Figure 8), while the administration during 3 days of a Gn-releasing hormone ( $\mathrm{GnRH})$ antagonist, which leads to the blockade of LH secretion, clearly decreased VEGF-A expression in the CL of primate ovaries (99). However, this effect of LH on ovarian VEGFA expression may be modulated or be dependent of local ovarian factors, such as ovarian sex steroids (100), as occurs in other tissues. This agrees with the concept that the VEGFA ovarian expression changes cyclically throughout a menstrual cycle (101).

\section{Pituitary Gonadotropins and Ovarian Angiogenesis}

The effects of LH on the ovarian production of VEGF-A have been confirmed in infertile, but otherwise normal, women to which recombinant $\mathrm{LH}(\mathrm{rLH})$ was administered (75 U/day) during the late follicular phase, induced by administration of $\mathrm{rFSH}$, in which the plasma and follicular liquid levels of VEGF-A, and its soluble receptor sFlt-1, were evaluated. The results obtained in this pioneer study indicated that $\mathrm{rLH}$ significantly increased the ratio VEGF-A/sFlt-1 in the follicular fluid, indicating that $\mathrm{LH}$ induced ovarian follicular angiogenesis (92), while inhibiting VEGF-A by treatment with truncated 


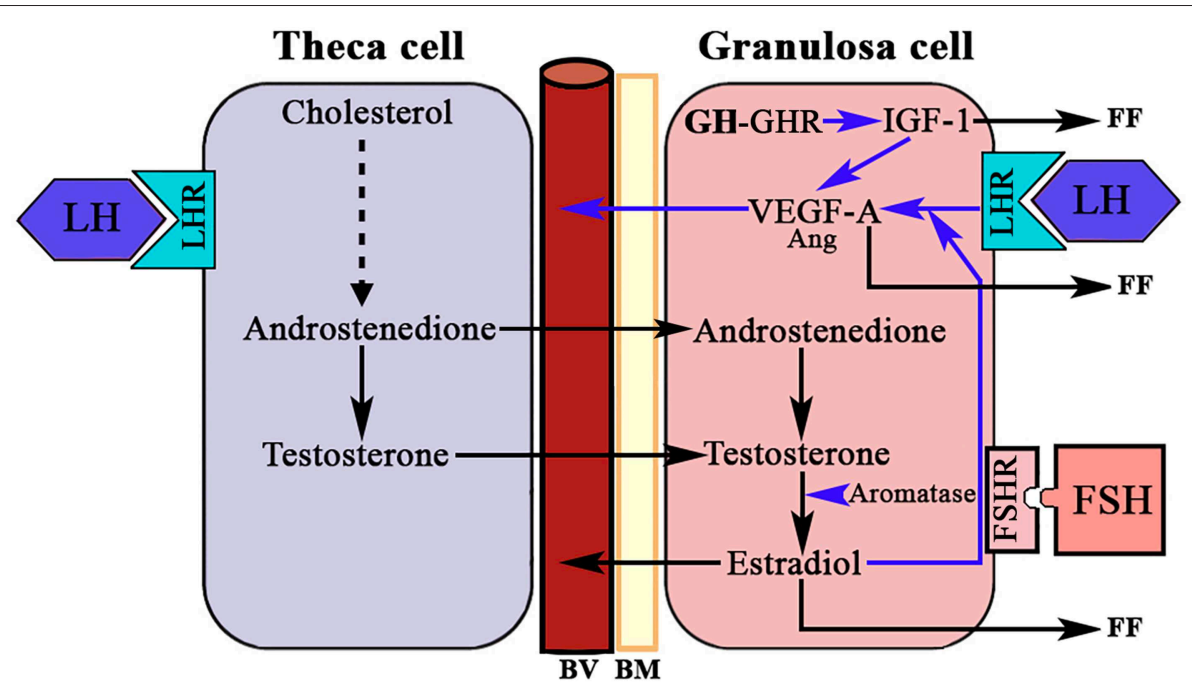

FIGURE 8 | LH, GH/IGF-1, and ovarian angiogenesis. The androgens produced in the theca cell under the stimulation of LH cross to the granulosa cell where, under the stimulation of FSH, they are aromatized to estradiol. In the growing follicle, there are receptors for LH that in combination with the produced E2 induces the expression of VEGF-A (mainly) and angiopoietin 1 (Ang). VEGF-A and Ang 1 induce the formation of new vessels (BV). There is a possibility that the GH produced in the granulosa cells induces the expression of IGF-1 who also favors the production of VEGF-A. VEGF-A and estradiol are released into small blood vessels, and both factors and IGF-1 are also released into the follicular fluid (FF). BV, blood vessels; BM, basement membrane; LHR, LH receptor; FSHR, FSH receptor; GHR, GH receptor; Blue arrows, stimulation.

Flt-1Fc (vascular endothelial growth factor trapA40) leads to the inhibition of angiogenesis during follicular development in primates (102).

Although the effects of $\mathrm{LH}$ on ovarian angiogenesis are clear, some data indicate that FSH may also play a role in this process. For instance, it has been demonstrated that the addition of $0.3 \mathrm{IU} / \mathrm{mL}$ of $\mathrm{FSH}$ during ovarian cryopreservation by vitrification increased the revascularization and follicular survival for mouse ovarian grafts up-regulating angiogenesis and ovarian survival factors (103); this may preserve ovarian fertility avoiding the follicular damage produced by chemotherapy and/or radiotherapy. Recently, it has been demonstrated that interleukin-6 (IL-6), a major factor in the regulation of VEGF-A expression (104), also promotes the expression of VEGF-A induced by FSH in bovine GCs (105), suggesting that there is a synergistic relationship between FSH and IL-6 in the regulation of VEGF-A expression. This effect of IL-6 on VEGF-A is dependent on the promotion by IL-6 on the VEGF-A regulators HIF-1 $\alpha$ (hypoxia inducible factor-1 $\alpha$ ) and COX2 (cyclooxygenase2), since their inhibition significantly decreases VEGF-A expression in GCs. In any case, it seems that a direct role of FSH in ovarian angiogenesis is restricted to particular non-physiological situations.

\section{Growth Hormone and Ovarian Angiogenesis}

Among the factors regulating VEGF family expression in humans $\mathrm{GH}$ plays a pivotal role, either directly or by inducing the expression of other proangiogenic factors, such as the Insulinlike growth factors (IGF-1 and IGF-2), FGF-2, epidermal growth factor (EGF), among others; moreover, $\mathrm{GH}$ is able to interact with receptors for Prolactin (PRL), which also is able to induce proangiogenic effects [for review, see (106)]. At this point, it is important to note that the pituitary secretion of GH is strongly potentiated by sex steroids, mainly E2, which in its free form (fE2) directly reaches the central nervous system (CNS), or is formed at this level from the hypothalamic aromatization of testosterone (9).

The possibility exists that systemic GH could induce ovarian VEGF-A expression, but this has not been demonstrated; perhaps because the own $\mathrm{GH}$ and its receptor are produced in the ovary in humans and bovines $(11,13,107)$. Moreover, the production of GH by ovaries is higher in GCs and oocytes, avascular follicular compartments, separated from the systemic circulation by the basal lamina (8) (Figure 4). Local expressions of GH and GHR have also been detected in the chicken ovary during sexual maturation in hens $(108,109)$ and fishes (110). Ovarian GH would act in an autocrine/paracrine way, so the hormone could play a role in the regulation of ovarian angiogenesis, as suggested by the fact that ovarian expression of the GH gene increases during follicular development (11), but significantly decreases when immature follicles reinitiated meiosis (111). The cyclic expression of follicular GH shows parallelism with the expression of follicular GHR in some species analyzed, including humans $(13,108,112)$. If this temporary pattern of ovarian GH-GHR correlates with changes in ovarian VEGF-A during a normal menstrual cycle, has not yet been established. However, the fact that the expression of VEGF-A in the follicle is related to the size of the follicle itself (Figure 7) is crucial to understand why angiogenesis is important and why $\mathrm{GH}$, the main hormone involved in tissue growth, should play an important role in the production of VEGF-A in the ovary (89). 
How the ovarian synthesis of GH is regulated is not known, although, as described above, GH-releasing hormone (GHRH) mRNA and GHRH receptor were found many years ago in humans and rats ovaries $(112,113)$. However, differently to that occurring at the hypothalamic-pituitary axis, ovarian GHRH does not seem to stimulate the synthesis and secretion of ovarian GH. In fact, recently it has been reported that a GHRH homodimer up-regulates the ovarian GHRH receptor increasing the development and maturation of follicles without affecting ovarian GH production, at least in an animal model (114). Another important GH secretagogue, such as ghrelin, has been found to increase $\mathrm{GH}$ secretion, but not $\mathrm{GH}$ synthesis, in porcine follicles in vitro (115), and ghrelin and its receptor have been found in the ovaries of pig and hen (116, 117). However, administration of ghrelin does not induce ovarian GH release in cultured ovaries in chicken (118). Paradoxically, ovarian GH stimulates ghrelin synthesis and secretion (115).

It cannot be ruled out that $\mathrm{GH}$ can act on the ovarian angiogenesis through one of the multiple mediators of the actions of the hormone, mainly IGF-1 (119). There is an ovarian production of IGF-1 and its receptor that induces angiogenesis by stimulating the production of VEGF-A in luteal cells, and also by stimulating the proliferation and differentiation of endothelial cells $(120,121)$. IGF-1 can act directly or as a mediator of the proangiogenic effects of $\mathrm{GH}$ (119). GH stimulates IGF-1 expression in rat and porcine granulosa cells $(61,122)$, and IGF-1 antibodies block the effect of $\mathrm{GH}$ on oocytes maturation in rat follicles (123). However, a study indicated that $\mathrm{GH}$ administration does not induce the synthesis of IGF-1 in human pre-menopausal ovaries (124), although previous studies showed that GH increases IGF-1 in follicular fluid in a number of species, including humans (Figure 5) [for review, see (14)]. Therefore, the GH effects on ovarian IGF-1 production may be exerted via endocrine or auto/paracrine actions.

Other proangiogenic growth factors, present in the ovary and whose transcription is induced by GH, such as FGF-2 and EGF, among others, seem not to play any key role on ovarian

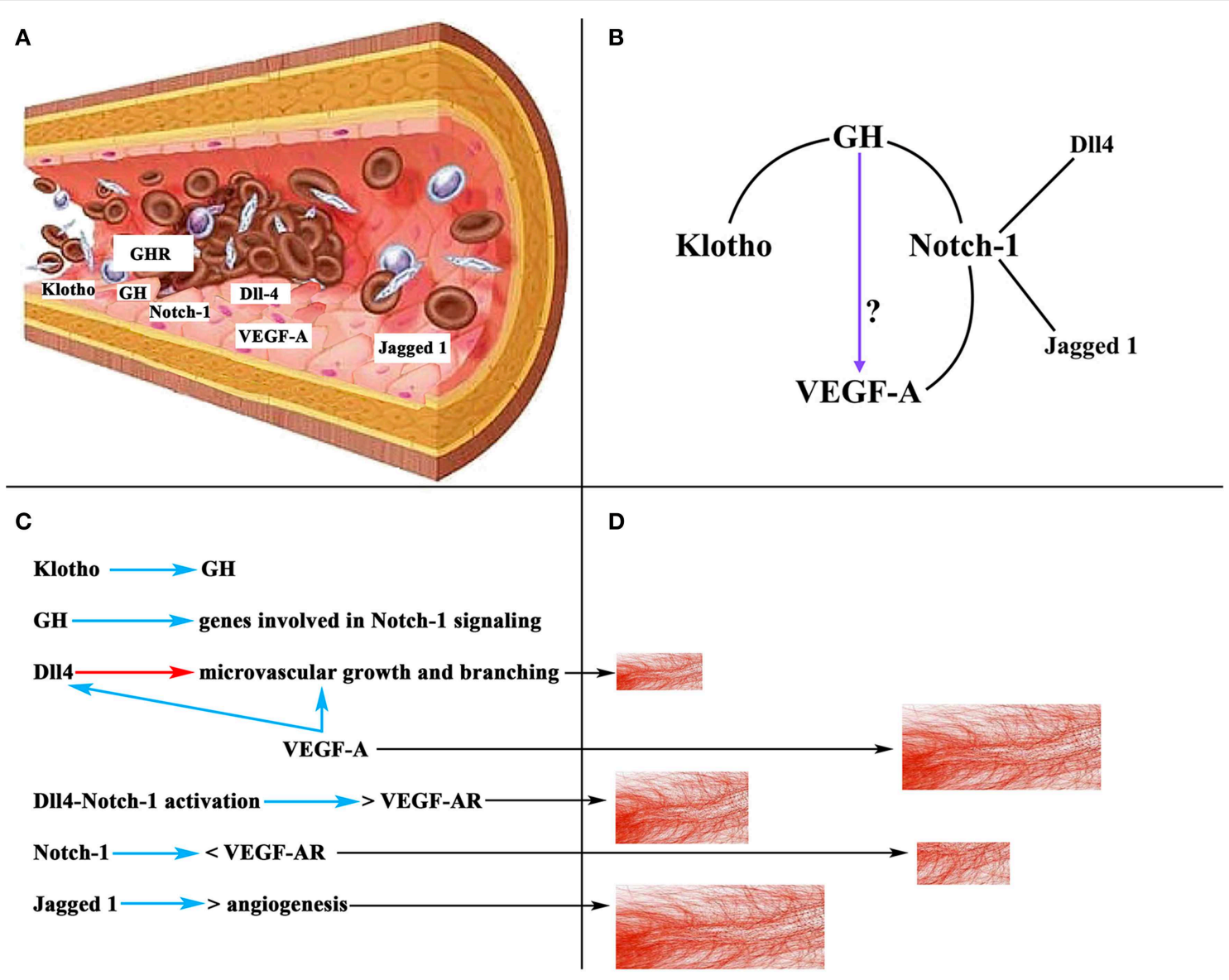

FIGURE 9 | Schematic representation of the action of VEGF-A, Notch-1 and its ligands on ovarian angiogenesis. (A) Section of an ovarian vascular vessel showing the expression of some factors involved in ovarian angiogenesis: Klotho, VEGF-A, Notch-1 and its ligands DII4 and Jagged 1, the receptor for GH (GHR), and presumably GH. (B) Relationships between Klotho, GH, Notch-1, and VEGF-A. These lead to the possibility that GH can act directly on the induction of the expression of VEGF-A in the endothelium of ovarian microvessels. (C) Summary of the actions of the factors mentioned in (A). Blue arrows, stimulation; Red arrow, inhibition; <, decrease; >, increase; VEGF-AR, receptor for VEGF. (D) Schematic representation of the growth of ovarian microvessels produced by the action of each one of the factors showed in (C) (black arrows). 
angiogenesis, although they can contribute to it; rather they participate in steroidogenesis, follicular development, and luteal function (125).

Of interest here is the relationship between GH, Notch1 , and VEGF-A. GH has been shown to regulate the ovarian expression of some genes involved in Notch-1 signaling to induce repair and regeneration of ovaries in mice with premature ovarian failure, as well as to induce E2 secretion and oocyte maturation (126). We will not analyze here the important effects that Notch-1 plays in the organism, but only the most important ones on angiogenesis in the ovary (127). In mice, during the follicular phase Notch-1 is expressed in the endothelium of the thecal layer, while in the luteal phase Notch1 has been detected in endothelial cells from new vessels of the CL and mature vessels of the thecal layer. In primates, two important Notch-1 ligands, such as delta-like protein Dll4 and Jagged $1(126,128)$, regulate angiogenesis directly in the endothelium, being specifically expressed at sites where this angiogenesis occurs (129). Dll4 regulates microvascular growth and branching induced by VEGF-A to prevent excessive branching that could lead to vascular dysfunction (130), whereas the blockade of Dll4 with an anti-Dll4 monoclonal antibody leads to an increase in luteal angiogenesis and a greater density of microvessels in the primate ovary (131). In turn, inhibiting Jagged 1 induces anti-angiogenic effects (132). Based on these data it is evident that Notch-1 plays an important role in ovarian angiogenesis. Curiously, there is a strong relationship between VEGF-A and Notch signaling. VEGF-A increases Dll4 expression in endothelial cells in vitro (133), and Dll4Notch-1 activation induces an increase in the expression of VEGF-A receptors in cultured endothelial cells (134), although activation of Notch-1 alone induces a reduction in the expression of VEGF-A receptor 2 (134). All this may be related to the need to form and maintain an adequate number and functionality of the ovarian blood vessels for a normal ovarian function in each of the phases of a menstrual cycle. In fact, ovarian angiogenesis is abnormal in women with polycystic ovarian syndrome; in these patients, there is an increase in follicular vascularization and vascular permeability (135). The excessive ovarian vascularization is responsible for the pathologic characteristics of the syndrome (127). Figure 9 shows a schematic representation of the effects of VEGF-A, Notch-1 and its ligands on ovarian angiogenesis.

As stated above, there is no evidence to show that GH induces the ovarian expression of VEGF-A; however, the possibility exists that ovarian vessels produce $\mathrm{GH}$ and this hormone promotes the expression of VEGF-A. In fact, the vascular endothelium is an important gland of internal secretion that produces a series of growth factors, including GH (136) (Figure 9A), that act in a paracrine/autocrine fashion. In addition, there is a specific GHR in the vascular endothelium (137, 138) (Figure 9A), and the damaged vascular endothelium produces Klotho, which stimulates the pituitary secretion of $\mathrm{GH}$, but perhaps also the production of endothelial GH to repair the vascular endothelium when it is damaged (3). Therefore, given the explained relationships between Notch-1 and VEGF-A, and Notch1 and $\mathrm{GH}$, and Klotho and $\mathrm{GH}$, it seems feasible that GH may directly participate in the regulation of ovarian angiogenesis (Figure 9B).

In summary, it is clear that adequate angiogenesis is critical in each of the phases that a primary follicle has to follow until it is transformed in an ovulatory follicle, ovulation occurs, and CL is formed and maintained until pregnancy takes place. Abnormal angiogenesis not only impedes the physiological evolution of this process but also may be the cause of pathologies such as infertility, polycystic ovarian syndrome and even ovarian cancer. Ovarian angiogenesis is very complex, and although VEGF-A plays a key role in it there are many factors, still little known, that can influence the actions of this protein both positively and negatively.

\section{CONCLUSIONS}

In conclusion, it is clear that $\mathrm{GH}$, expressed in the ovary and/or systemic GH, is very important in all stages of ovarian development and normal functioning until menopause. The ovarian effects of GH can be exerted by the hormone itself and/or through its mediators. Of interest is the bidirectional inverse relationship between the actions of GH and BMP at the ovarian level, as well as their actions on the secretion of gonadotropins. It is likely that $\mathrm{GH}$ can be a very important factor as adjuvant therapy for IVF and embryo transfer in infertile women poor ovarian responders. In addition, ovarian angiogenesis plays a key role in the normal ovarian functioning since puberty begins until menopause. The formation and functionality of the ovarian vessels depend mainly on VEGF-A, although Angiopoietins also play a role in ovarian angiogenesis. Ovarian expression of VEGF-A is regulated by LH together with sex steroids, but GH also appears to be (directly or indirectly) actively involved in this process.

\section{AUTHOR CONTRIBUTIONS}

JD conceived, structured, and wrote the text. DC contributed to writing the section devoted to Ovarian Angiogenesis.

\section{FUNDING}

This review has been funded by Foundation Foltra (Teo, Spain), grant F2019-6.

\section{ACKNOWLEDGMENTS}

We acknowledge the Foundation Foltra (Teo, Spain) for the help provided to write this review. 


\section{REFERENCES}

1. Raben MS. Treatment of a pituitary dwarf with human growth hormone. $J$ Clin Endocrinol Metab. (1958) 18:901-3.

2. Devesa J, Almengló C, Devesa P. Multiple effects of growth hormone in the body: is it really the hormone for growth? Clin Med Insights: Endocrinol Diabetes. (2016) 9:47-71. doi: 10.4137/CMED.S 38201

3. Caicedo D, Díaz O, Devesa P, Devesa J. Growth hormone (GH) and cardiovascular system. Int J Mol Sci. (2018) 19:E290. doi: 10.3390/ijms19010290

4. Devesa J, Díaz MJ, Odriozola A, Arce V, Lima L. Neurorregulación de la secreción de hormona de crecimiento $(\mathrm{GH})$ y expresión del gen de esta hormona en pro- y eucariotas. Endocrinología. (1991) 38:33-41.

5. Lobie PE, Mertani H, Morel G, Morales-Bustos O, Norstedt G, Waters MJ. Receptor-mediated nuclear translocation of growth hormone. J Biol Chem. (1994) 269:21330-9.

6. Mertani H, Raccurt M, Abbate A, Kindblom JM, Törnell J, Billestrup N, et al. Nuclear translocation and retention of growth hormone. Endocrinology. (2003) 144:3182-95. doi: 10.1210/en.2002-221121

7. Lan H, Liu H, Hong P, Li R, Zheng X. Porcine growth hormone induces the nuclear localization of porcine growth hormone receptor in vivo. AsianAustralas J Anim Sci. (2018) 31:499-504. doi: 10.5713/ajas.17.0585

8. Lobie PE, Breipohl W, Aragón JG, Waters MJ. Cellular localization of the growth hormone receptor/binding protein in the male and female reproductive systems. Endocrinology. (1990) 126:2214-21. doi: 10.1210/endo-126-4-2214

9. Devesa J, Lima L, Tresguerres JA. Neuroendocrine control of growth hormone secretion in humans. Trends Endocrinol Metab. (1992) 3:175-83.

10. Fraser HM. Regulation of the ovarian follicular vasculature. Reprod Biol Endocrinol. (2006) 4:18. doi: 10.1186/1477-7827-4-18

11. Izadyar F, Zhao, J, van Tool HT, Colenbrander B, Bevers MM. Messenger RNA expression and protein localization of growth hormone in bovine ovarian tissue and in cumulus oocyte complexes (COCs) during in vitro maturation. Mol Reprod Dev. (1999) 53:398-406.

12. Ménézo YJ, Nicollet B, Rollet J, Hazout A. Pregnancy and delivery after in vitro maturation of naked ICSI-GV oocytes with GH and transfer of a frozen thawed blastocyst: case report. J Assist Reprod Genet. (2006) 23:479. doi: 10.1007/s10815-005-9014-0

13. Abir R, Garor R, Felz C, Nitke S, Krissi H, Fisch B. Growth hormone and its receptor in human ovaries from fetuses and adults. Fertil Steril. (2008) 90:1333-9. doi: 10.1016/j.fertnstert.2007.08.011

14. Hull KL, Harvey S. Growth hormone: roles in female reproduction. $J$ Endocrinol. (2001) 168:1-23. doi: 10.1155/2014/234014

15. Wit JM, Massarano AA, Kamp GA, Hindmarsh PC, vanEs A, Brook CG, et al. Growth hormone secretion in patients with Turner's syndrome as determined by time series analysis. Acta Endocrinol. (1992) 127:7-12.

16. Wilson ME. The impact of the GH-IGF-I axis on gonadotropin secretion: inferences from animal models. J Pediatr Endocrinol Metab. (2001) 14:11540. doi: 10.1515/JPEM.2001.14.2.115

17. Chandrashekar V, Zaczek D, Bartke A. The consequences of altered somatotropic system on reproduction. Biol Reprod. (2004) 71:17-27. doi: 10.1095/biolreprod.103.027060

18. Gutiérrez S, Mukdsi JH, Aoki A, Torres AI, Soler AP, Orgnero EM. Ultrastructural immunolocalization of IGF-1 and insulin receptors in rat pituitary culture: evidence of a functional interaction between gonadotroph and lactotroph cells. Cell Tissue Res. (2007) 327:12132. doi: 10.1007/s00441-006-0283-4

19. Wolfe A, Divall S, Wu S. The regulation of reproductive neuroendocrine function by insulin and insulin-like growth factor-1 (IGF-1). Front Neuroendocrinol. (2014) 35:558-72. doi: 10.1016/j.yfme.2014.05.007

20. Zhen S, Zakaria M, Wolfe A, Radovick S. Regulation of gonadotropinreleasing hormone $(\mathrm{GnRH})$ gene expression by insulin-like growth factor I in a cultured GnRH-expressing neuronal cell line. Mol Endocrinol. (1997) 11:1145-55. doi: 10.1210/mend.11.8.9956

21. Longo KM, Sun Y, Gore AC. Insulin-like growth factor-I effects on gonadotropin-releasing hormone biosynthesis in GT1-7 cells. Endocrinology. (1998) 139:1125-32.
22. Pathipati P, Gorba T, Scheepens A, Goffin V, Sun Y, Fraser M. Growth hormone and prolactin regulate human neural stem cell regenerative activity. Neuroscience. (2011) 190:409-27. doi: 10.1016/j.neuroscience.2011.05.029

23. Silveira MA, Zampieri TT, Furigo IC, Abdulkader F, Donato J Jr, Frazao R. Acute effects of somatomammotropin hormones on neuronal components of the hypothalamic-pituitary-gonadal axis. Brain Res. (2019) 1714:2107. doi: 10.1016/j.brainres.2019.03.003

24. Bartke A. Role of growth hormone and prolactin in the control of reproduction: what are we learning from transgenic and knock-out animals? Steroids. (1999) 64:598-604.

25. Bachelot A, Monget P, Imbert-Bollore P, Coshigano K, Kopchick JJ, Kelly $\mathrm{PA}$, et al. Growth hormone is required for ovarian follicular growth. Endocrinology. (2002) 143:4104-12. doi: 10.1210/en.2002-220087

26. Spiliotis BE. Growth hormone insufficiency and its impact on ovarian function. Ann N Y Acad Sci. (2003) 997:77-84. doi: 10.1196/annals.1290.009

27. Giampietro A, Milardi D, Bianchi A, Fusco A, Cimino V, Valle D, et al. The effect of treatment with growth hormone on fertility outcome in eugonadal women with growth hormone deficiency: report of four cases and review of the literature. Fertil Steril. (2009) 91:390.e711. doi: 10.1016/j.fertnstert.2008.09.065

28. Sizonenko PC. Physiology of puberty. J Endocrinol Invest. (1989) 12:59-63.

29. Apter D, Bützow TL, Laughlin GA, Yen SS. Gonadotropin-releasing hormone pulse generator activity during pubertal transition in girls: pulsatile and diurnal patterns of circulating gonadotropins. J Clin Endocrinol Metab. (1993) 76:940-9. doi: 10.1210/jcem.76.4.8473410

30. Herbison AE. Control of puberty onset and fertility by gonadotropin-releasing hormone neurons. Nat Rev Endocrinol. (2016) 12:452-66. doi: 10.1038/nrendo.2016.70

31. Choi JH, Yoo HW. Control of puberty: genetics, endocrinology, and environment. Curr Opin Endocrinol Diabetes Obes. (2013) 20:62-8. doi: 10.1097/MED.ob013e32835b7ec7

32. Ong KK, Elks CE, Li S, Zhao JH, Luan J, Andersen LB, et al. Genetic variation in LIN28B is associated with the timing of puberty. Nat Genet. (2009) 4:729-33. doi: 10.1038/ng.382

33. Elks CE, Perry JR, Sulem P, Chasman DI, Franceschini N, He C, et al. Thirty new loci for age at menarche identified by a meta-analysis of genome-wide association studies. Nat Genet. (2010) 42:1077-85. doi: 10.1038/ng.714

34. Perry JR, Day F, Elks CE, Sulem P, Thompson DJ, Ferreira T, et al. Parentof-origin-specific allelic associations among 106 genomic loci for age at menarche. Nature. (2014) 514:92-7. doi: 10.1038/nature13545

35. Kaplowitz PB, Slora EJ, Wasserman RC, Pedlow SE, Herman-Giddens ME. Earlier onset of puberty in girls: relation to increased body mass index and race. Pediatrics. (2001) 108:347-53. doi: 10.1542/peds.108.2.347

36. He Q, Karlberg J. BMI in childhood and its association with height gain, timing of puberty, and final height. Pediatr Res. (2001) 49:24451. doi: 10.1203/00006450-200102000-00019

37. Casanueva FF, Borrás CG, Burguera B, Muruais C, Fernández M, Devesa J. Steroids and neuroendocrine function in anorexia nervosa. J Steroid Biochem. (1987) 27:635-40.

38. Green ED, Maffei M, Braden VV, Proenca R, DeSilva U, Zhang Y, et al. The human obese $(\mathrm{OB})$ gene: RNA expression pattern and mapping on the physical, cytogenetic, and genetic maps of chromosome 7. Genome Res. (1995) 5:5-12.

39. Barash IA, Cheung CC, Weigle DS, Ren H, Kabigting EB, Kuijper JL, et al. Leptin is a metabolic signal to the reproductive system. Endocrinology. (1996) 137:3144-7. doi: 10.1210/endo.137.7.8770941

40. Gavela-Pérez T, Navarro P, Soriano-Guillén L, Garcés C. High prepubertal Leptin levels are associated with earlier menarcheal age. J Adolesc Health. (2016) 59:177-81. doi: 10.1016/j.adohealth.2016.03.042

41. Blüher S, Mantzoros CS. Leptin in reproduction. Curr Opin Endocrinol Diabetes Obes. (2007) 14:458-64. doi: 10.1097/MED.ob013e3282flgfdc

42. Castellano JM, Roa J, Luque RM, Dieguez C, Aguilar E, Pinilla L, et al. KISS-1/kisspeptins and the metabolic control of reproduction: physiologic roles and putative physiopathological implications. Peptides. (2009) 30:13945. doi: 10.1016/j.peptides.2008.06.007

43. Sharara FI, Giudice LC. Role of growth hormone in ovarian physiology and onset of puberty. J Soc Gynecol Investig. (1997) 4:2-7. doi: 10.1016/S1071-5576(96)00059-7 
44. Lee M. Growth hormone deficiency as the only identifiable cause for primary amenorrhea. J Pediatr Adolesc Gynecol. (2000) 13:93. doi: 10.1016/S1083-3188(00)00025-5

45. Li W, Liu Q, Deng X, Chen Y, Liu S, Story M. Association between obesity and puberty timing: a systematic review and meta-analysis. Int J Environ Res Public Health. (2017) 14:E1266. doi: 10.3390/ijerph141 01266

46. Ong KK, Emmett P, Northstone K, Golding J, Rogers I, Ness AR, et al. Infancy weight gain predicts childhood body fat and age at menarche in girls. J Clin Endocrinol Metab. (2009) 94:1527-32. doi: 10.1210/jc.2008-2489

47. Davison KK, Susman EJ, Birch LL. Percent body fat at age 5 predicts earlier pubertal development among girls at age 9. Pediatrics. (2003) 111:81521. doi: $10.1542 /$ peds.111.4.815

48. Flom JD, Cohn BA, Tehranifar P, Houghton LC, Wei Y, Protacio A, et al. Earlier age at menarche in girls with rapid early life growth: Cohort and within sibling analyses. Ann Epidemiol. (2017) 27:18793. doi: 10.1016/j.annepidem.2017.01.004

49. Barcellos Gemelli IF, Farias Edos S, Souza OF. Age at menarche and its association with excess weight and body fat percentage in girls in the southwestern region of the Brazilian Amazon. J Pediatr Adolesc Gynecol. (2016) 29:482-8. doi: 10.1016/j.jpag.2016.02.011

50. Marcovecchio ML, Chiarelli F. Obesity and growth during childhood and puberty. World Rev Nutr Diet. (2013) 106:135-41. doi: 10.1159/000342545

51. Monte APO, Barros VRP, Santos JM, Menezes VG, Cavalcante AYP, Gouveia $\mathrm{BB}$, et al. Immunohistochemical localization of insulin-like growth factor1 (IGF-1) in the sheep ovary and the synergistic effect of IGF-1 and FSH on follicular development in vitro and LH receptor immunostaining. Theriogenology. (2019) 129:61-9. doi: 10.1016/j.theriogenology.2019.02.005

52. Jimenez CR, de Azevedo JL, Ciro Alexandre Alves T, Penitente-Filho JM, Gonçalves WG. Sequential medium with GH and IGF-1 improved in vitro development of bovine preantral follicles enclosed in ovarian tissue. Reprod Domest Anim. (2018) 53:1103-13. doi: 10.1111/rda.13210

53. Barreca A, Artini PG, Del Monte P, Ponzani P, Pasquini P, Cariola $\mathrm{G}$, et al. In vivo and in vitro effect of growth hormone on estradiol secretion by human granulose cells. J Clin Endocrinol Metab. (1993) 77:617. doi: $10.1210 /$ jcem.77.1.8325961

54. Eppig JJ. Oocyte control of ovarian follicular development and function in mammals. Reproduction. (2001) 122:829-38. doi: 10.1530/reprod/122.6.829

55. Gilchrist RB, Ritter LJ, Myllymaa S, Kaivo-Oja N, Dragovic RA, Hickey TE, et al. Molecular basis of oocyte-paracrine signalling that promotes granulosa cell proliferation. J Cell Sci. (2006) 119:3811-21. doi: 10.1242/jcs.03105

56. Sirotkin AV. Control of reproductive processes by growth hormone: extra- and intracellular mechanisms. Vet J. (2005) 170:307-17. doi: 10.1016/j.tvjl.2004.05.014

57. Silva JR, Figueiredo JR, van den Hurk R. Involvement of growth hormone (GH) and insulin-like growth factor (IGF) system in ovarian folliculogenesis. Theriogenology. (2009) 71:1193-208. doi: 10.1016/j.theriogenology.2008.12.015

58. Slot KA, Kastelijn J, Bachelot A, Kelly PA, Binart N, Teerds KJ. Reduced recruitment and survival of primordial and growing follicles in GH receptordeficient mice. Reproduction. (2006) 131:525-32. doi: 10.1530/rep.1.00946

59. Lanzone A, Fortini A, Fulghesu AM, Soranna L, Caruso A, Mancuso S. Growth hormone enhances estradiol production follicle-stimulating hormone-induced in the early stage of the follicular maturation. Fertil Steril. (1996) 66:948-53.

60. Yoshimura Y. Insulin-like growth factors and ovarian physiology. J Obstet Gynaecol Res. (1998) 24:305-23.

61. Nakamura E, Otsuka F, Inagaki K, Miyoshi T, Matsumoto Y, Ogura K, et al. Mutual regulation of growth hormone and bone morphogenetic protein system in steroidogenesis by rat granulosa cells. Endocrinology. (2012) 153:469-80. doi: 10.1210/en.2011-1646

62. Takeda M, Otsuka F, Takahashi H, Inagaki K, Miyoshi T, Tsukamoto $\mathrm{N}$, et al. Interaction between gonadotropin-releasing hormone and bone morphogenetic protein- 6 and-7 signaling in LßT2 gonadotrope cells. Mol Cell Endocrinol. (2012) 348:147-54. doi: 10.1016/j.mce.2011.08.001.

63. Otsuka F, Inagaki K. Unique bioactivities of bone morphogenetic proteins in regulation of reproductive functions. Reprod Med Biol. (2011) 10:13142. doi: 10.1007/s12522-011-0082-9
64. Regan SLP, Knight PG, Yovich JL, Leung Y, Arfuso F, Dharmarajan A. Involvement of Bone Morphogenetic Proteins (BMP) in the regulation of ovarian function. Vitam Horm. (2018) 107:227-61. doi: 10.1016/bs.vh.2018.01.015

65. Shirazi A, Shams-Esfandabadi N, Ahmadi E, Heidari B. Effects of growth hormone on nuclear maturation of ovine oocytes and subsequent embryo development. Reprod Domest Anim. (2010) 45:530-6. doi: 10.1111/j.1439-0531.2008.0 1290.x

66. Ménézo YJ, el Mouatassim S, Chavrier M, Servy EJ, Nicolet B. Human oocytes and preimplantation embryos express mRNA for growth hormone receptor. Zygote. (2003) 11:293-7. doi: 10.1016/S0015-0282(02)03948-1

67. De Prada JK, VandeVoort CA. Growth hormone and in vitro maturation of rhesus macaque oocytes and subsequent embryo development. J Assist Reprod Genet. (2008) 25:145-58. doi: 10.1007/s10815-008-9208-3

68. Izadyar F, Hage WJ, Colenbrander B, Bevers MM. The promotory effect of growth hormone on the developmental competence of in vitro matured bovine oocytes is due to improved cytoplasmic maturation. Mol Reprod Dev. (1998) 49:444-53. doi: 10.1002/(SICI)1098-2795(199804)49:4<444::AIDMRD12>3.0.CO:2-U

69. Almog B, Gold R, Tajima K, Dantes A, Salim K, Rubinstein M, et al. Leptin attenuates follicular apoptosis and accelerates the onset of puberty in immature rats. Mol Cell Endocrinol. (2001) 183:17991. doi: $10.1016 / \mathrm{S} 0303-7207(01) 00543-3$

70. Ovesen P, Ingerslev HJ, Orskov H, Ledet T. Effect of growth hormone on steroidogenesis, insulin-like growth factor-I (IGF-I) and IGF-binding protein-1 production and DNA synthesis in cultured human luteinized granulose cells. J Endocrinol. (1994) 140:313-9. doi: 10.1677/joe.0.1400313

71. Cui N, Li AM, Luo ZY, Zhao ZM, Xu YM, Zhang J, et al. Effects of growth hormone on pregnancy rates of patients with thin endometrium. $J$ Endocrinol Invest. (2019) 42:27-35. doi: 10.1007/s40618-018-0877-1

72. Markham KE, Kaye PL. Growth hormone, insulin-like growth factor I and cell proliferation in the mouse blastocyst. Reproduction. (2003) 125:327-36. doi: $10.1530 /$ rep.0.1250327

73. Giustina A, Veldhuis JD. Pathophysiology of the neuroregulation of growth hormone secretion in experimental animals and the human. Endocr Rev. (1998) 19:717-97. doi: 10.1210/edrv.19.6.0353

74. Maggio M, Ble A, Ceda GP, Metter EJ. Decline in insulin-like growth factor-1 levels across adult life span in two large population studies. J Gerontol A Biol Sci Med Sci. (2006) 61:182-3. doi: 10.1093/gerona/61.2.182

75. Bartke A, Sun LY, Longo V. Somatotropic signaling: trade-offs between growth, reproductive development, and longevity. Physiol Rev. (2013) 93:571-98. doi: 10.1152/physrev.00006.2012

76. Veldhuis JD, Bowers CY. Human GH pulsatility: an ensemble property regulated by age and gender. J Endocrinol Invest. (2003) 26:799813. doi: 10.1007/BF03345229

77. Veldhuis JD, Iranmanesh A, Bowers CY. Joint mechanisms of impaired growth-hormone pulse renewal in aging men. J Clin Endocrinol Metab. (2005) 90:4177-183. doi: 10.1210/jc.2005-0336

78. Zadik Z, Chalew SA, McCarter RJ Jr, Meistas M, Kowarski AA. The influence of age on the 24-hour integrated concentration of growth hormone in normal individuals. J Clin Endocrinol Metab. (1985) 60:5136. doi: 10.1210/jcem-60-3-513

79. Shah N, Evans WS, Veldhuis JD. Actions of estrogen on pulsatile, nyctohemeral, and entropic modes of growth hormone secretion. Am J Physiol. (1999) 276:R1351-8. doi: 10.1152/ajpregu.1999.276.5.R1351

80. Veldhuis JD, Erickson D, Yang R, Takahashi P, Bowers C. Endogenous estrogen regulates somatostatin-induced rebound $\mathrm{GH}$ secretion in postmenopausal women. J Clin Endocrinol Metab. (2016) 101:4298-304. doi: 10.1210/jc.2016-2080

81. Muniyappa R, Sullivan SD, Tella SH, Abel BS, Harman SM, Blackman MR. Effects of growth hormone administration on luteinizing hormone secretion in healthy older men and women. Physiol Rep. (2017) 5:e13516. doi: 10.14814/phy2.13516

82. Owen EJ, West C, Mason BA, Jacobs HS. Co-treatment with growth hormone of sub-optimal responders in IVF-ET. Hum Reprod. (1991) 6:524-8.

83. Owen EJ, Shoham Z, Mason BA, Ostergaard H, Jacobs HS. Cotreatment with growth hormone, after pituitary suppression, for ovarian stimulation in in 
vitro fertilization: a randomized, double-blind, placebo-control trial. Fertil Steril. (1991) 56:1104-10.

84. Regan SLP, Knight PG, Yovich JL, Arfuso F, Dharmarajan A. Growth hormone during in vitro fertilization in older women modulates the density of receptors in granulosa cells, with improved pregnancy outcomes. Fertil Steril. (2018) 110:1298-310. doi: 10.1016/j.fertnstert.2018.08.018

85. Cai MH, Liang XY, Wu, YQ, Huang R, Yang X. Six-week pretreatment with growth hormone improves clinical outcomes of poor ovarian responders undergoing in vitro fertilization treatment: A self-controlled clinical study. J Obstet Gynaecol Res. (2019) 45:376-81. doi: 10.1111/jog.13823

86. Liu X, Bai H, Xie J, Shi, J. Growth hormone co-treatment on controlled ovarian stimulation in normal ovarian response women can improve embryo quality. Gynecol Endocrinol. (2019) 23:1-5. doi: 10.1080/09513590.2019.1590545

87. Li X-L, Wang L, Lv F, Huang XM, Wang LP, Pan Y, et al. The influence of different growth hormone addition protocols to poor ovarian responders on clinical outcomes in controlled ovary stimulation cycles: A systematic review and meta-analysis. Medicine (Baltimore). (2017) 96:e6443. doi: 10.1097/MD.0000000000006443

88. Augustin HG. Vascular morphogenesis in the ovary. Baillieres Best Pract Res Clin Obstet Gynaecol. (2000) 14:867-82. doi: 10.1053/beog.2000.0132

89. Kaczmarek MM, Schams D, Ziecik AJ. Role of vascular endotelial growth factor in ovarian physiology - an overview. Reprod Biol. (2005) 5:111-36.

90. Gospodarowicz D, Cheng J, Lui GM. Corpus luteum angiogenic factor is related to fibroblast growth factor. Endocrinology. (1985) 117:2383-91.

91. Reynolds LP, Redmer DA. Growth and development of the corpus luteum. $J$ Reprod Fertil Suppl. (1999) 54:181-91.

92. Suzuki T, Sasano H, Takaya R, Fukaya T, Yajima A, Nagura H. Cyclic changes of vasculature and vascular phenotypes in normal human ovaries. Hum Reprod. (1998) 13:953-9.

93. Gaytán F, Morales C, García-Pardo L, Reymundo C, Bellido C, SánchezCriado JE. A quantitative study of changes in the human corpus luteum microvasculature during the menstrual cycle. Biol Reprod. (1999) 60:914-9.

94. Ferrara N. Vascular endotelial growth factor. Trends Cardiovasc Med. (1993) 3:244-50.

95. Robinson RS, Woad KJ, Hammond AJ, Laird M, Hunter MG, Mann GE. Angiogenesis and vascular function in the ovary. Reproduction. (2009) 138:869-81. doi: 10.1530/REP-09-0283

96. Hazzard TM, Stouffer RL. Angiogenesis in ovarian follicular and luteal development. Baillieres Best Pract Res Clin Obstet Gynaecol. (2000) 14:883900. doi: 10.1053/beog.2000.0133

97. Maisonpierre PC, Suri C, Jones PF, Bartunkova S, Wiegand SJ, Radziejewski $\mathrm{C}$, et al. Angiopoietin-2, a natural antagonist for Tie2 that disrupts in vivo angiogenesis. Science. (1997) 277:55-60.

98. Hazzard TM, Molskness TA, Chaffin CL, Stouffer RL. Vascular endotelial growth factor (VEGF-A) and angiopoietin regulation by gonadotrophin and steroids in macaque granulosa cells during the peri-ovulatory interval. $\mathrm{Mol}$ Hum Reprod. (1999) 5:1115-21.

99. Ravindranath N, Little-Ihrig L, Phillips HS, Ferrara N, Zeleznik AJ. Vascular endothelial growth factor messenger ribonucleic acid expression in the primate ovary. Endocrinology. (1992) 131:254-60.

100. Burr JH Jr, Davies JI. The vascular system of the rabbit ovary and its relationship to ovulation. Anat Rec. (1951) 111:273-97.

101. Stouffer RL, Martínez-Chequer JC, Molskness TO, Xu F, Hazzard TM. Regulation and action of angiogenic factors in the primate ovary. Arch Med Res. (2001) 32:567-75. doi: 10.1016/S0188-4409(01)00323-X

102. Gutman G, Barak V, Maslovitz S, Amit A, Lessing JB, Geva E. Regulation of vascular endotelial growth factor-A and its soluble receptor sFlt-1 by luteinizing hormone in vivo: implication for ovarian follicle angiogenesis. Fertil Steril. (2008) 89:922-6. doi: 10.1016/j.fertnstert.2007.03.097

103. Wulff C, Wiegand SJ, Saunders PTK, Scobie GA, Fraser HM. Angiogenesis during follicular development in the primate and its inhibition by treatment with truncated Flt-1FC (vascular endothelial growth factor trapA40). Endocrinology. (2001) 142:3244-54. doi: 10.1210/endo.142.7.8258

104. Zhang H, Yang Y, Ma W, Wu H, Zheng X, Hei C, et al. The revascularization and follicular survival of mouse ovarian grafts treated with FSH during cryopreservation by vitrification. Cryo Let. (2016) 37:88-102.
105. Cohen T, Nahari D, Cerem LW, Neufeld G, Levi B-Z. Interleukin 6 induces the expression of Vascular Endothelial Growth Factor. J Biol Chem. (1996) 271:736-41.

106. Yang $\mathrm{M}$, Wang L, Wang X, Wang X, Yang Z, Li J. IL-6 promotes FSH-Induced VEGF-A expression through JAK/STAT3 signaling pathway in bovine granulosa cells. Cell Physiol Biochem. (2017) 44:293-302. doi: 10.1159/000484885

107. Caicedo D, Devesa P, Arce VM, Requena J, Devesa J. Chronic limbthreatening ischemia could benefit from growth hormone therapy for wound healing and limb salvage. Ther Adv Cardiovasc Dis. (2018) 12:5372. doi: $10.1177 / 1753944717745494$

108. Schwärzler P, Untergasser G, Hermann M, Dirnhofer S, Abendstein B, Madersbacher S, et al. Selective growth hormone/placental lactogen gene transcription and hormone production in pre- and postmenopausal human ovaries. J Clin Endocrinol Metab. (1997) 82:3337-41.

109. Hrabia A, Paczoska-Eliasiewicz HE, Berghman LR, Harvey S, Rzasa J. Expression and localization of growth hormone and its receptors in the chicken ovary during sexual maturation. Cell Tissue Res. (2008) 332:31728. doi: 10.1007/s00441-008-0595-7

110. Luna M, Martínez-Moreno CG, Ahumada-Solórzano MS, Harvey S, Carranza M, Arámburo C. Extrapituitary growth hormone in the chicken reproductive system. Gen Comp Endocrinol. (2014) 203:608. doi: 10.1016/j.ygcen.2014.02.021

111. Xu Y, Wang B, Liu X, Shi B, Zang K. Evidences for involvement of growth hormone and insulin-like growth factor in ovarian development of starry flounder (Platichthys stellatus). Fish Biol Biochem. (2017) 43:52737. doi: 10.1007/s10695-016-0307-2

112. Zhu G, Liu S, Jiang Y, Yang H, Li J. Growth hormone pathway gene expression varies in porcine cumulus-oocyte complexes during in vitro maturation. In Vitro Cell Dev Biol Anim. (2008) 44:3058. doi: 10.1007/s11626-008-9130-0

113. Moretti C, Bagnato A, Solan N, Frajese G, Catt KJ. Receptor-mediated actions of growth hormone releasing factor on granulosa cell differentiation. Endocrinology. (1990) 127:2117-26.

114. Bagnato A, Moretti C, Ohnishi J, Frajese G, Catt KJ. Expression of the growth hormone-releasing hormone gene and its peptide product in the rat ovary. Endocrinology. (1992) 130: 1097-102.

115. Zhang JH, Zhang XD, Yue LN, Guo XY, Tang JX, Guo LR, et al. Novel hGHRH homodimer promotes fertility of female infertile hamster by upregulating ovarian GHRH receptor without triggering $\mathrm{GH}$ secretion. Eur J Pharm Sci. (2018) 117:341-50. doi: 10.1016/j.ejps.2018.03.012

116. Rak A, Gregoraszczuk EŁ. Local feedback loop of ghrelin-GH in the pig ovary: action on estradiol secretion, aromatase activity and cell apoptosis. Growth Horm IGF Res. (2008) 18:221-7. doi: 10.1016/j.ghir.2007.09.004

117. Rak A, Szczepankiewicz D, Gregoraszczuk EŁ. Expression of ghrelin receptor, GHSR-1a, and its functional role in the porcine ovarian follicles. Growth Horm IGF Res. (2009) 19:68-76. doi: 10.1016/j.ghir.2008.08.006

118. Sirotkin AV, Grossmann R, María-Peon MT, Roa J, Tena-Sempere M, Klein $\mathrm{S}$. Novel expression and functional role of ghrelin in chicken ovary. Mol Cell Endocrinol. (2006) 257-8:15-25. doi: 10.1016/j.mce.2006.06.004

119. Sirotkin AV, Harrath AH, Grossmann R. Metabolic status and ghrelin regulate plasma levels and release of ovarian hormones in layer chicks. Physiol Res. (2017) 66:85-92. Available online at: www.biomed.cas.cz/ physiolres

120. Delafontaine P, Song YH, Li Y. Expression, regulation, and function of IGF1, IGF-1R, and IGF-1 binding proteins in blood vessels. Arterioscler Thromb Vasc Biol. (2004) 24:435-44. doi: 10.1161/01.ATV.0000105902.89459.09

121. Schams D, Kosmann M, Berisha B, Amselgruber WM, Miyamoto A. Stimulatory and synergistic effects of luteinising hormone and insulin like growth factor 1 on the secretion of vascular endothelial growth factor and progesterone of cultured bovine granulosa cells. Exp Clin Endocrinol Diabetes. (2001) 109:155-62. doi: 10.1055/s-2001-14839

122. Schams D, Berisha B, Kosmann M, Amselgruber WM. Expression and localization of IGF family members in bovine antral follicles during final growth and in luteal tissue during different stages of estrous cycle and pregnancy. Domest Anim Endocrinol. (2002) 22:51-72. doi: 10.1016/S0739-7240(01)00116-3 
123. Ptak A, Kajta M, Gregoraszczuk EL. Effect of growth hormone and insulinlike growth factor-I on spontaneous apoptosis in cultured luteal cells collected from early, mature, and regressing porcine corpora lutea. Anim Reprod Sci. (2004) 80:267-79. doi: 10.1016/j.anireprosci.2003.07.006

124. Apa R, Lanzone A, Miceli F, Caruso A, Mancuso S, Canipari R. Growth hormone induction of rat granulosa cell tissue-plasminogen activator expression and progesterone synthesis. Mol Cell Endocrinol. (1994) 99:153-9.

125. Peñarrubia J, Balasch J, García-Bermúdez M, Casamitjana R, Vanrell JA, Hernandez E. Growth hormone does not increase the expression of insulin-like growth factors and their receptor genes in the pre-menopausal human ovary. Hum Reprod. (2000) 15:1241-46. doi: 10.1093/humrep/15. 6.1241

126. Galvão AM, Skarzynski D, Ferreira-Dias G. luteolysis and the auto-, paracrine role of cytokines from tumor necrosis factor $\alpha$ and transforming growth factor $\beta$ superfamilies. Vitam Horm. (2018) 107:287-315. doi: 10.1016/bs.vh.2018.01.001

127. Liu T, Wang S, Zhang L, Guo L, Yu Z, Chen C, et al. Growth hormone treatment of premature ovarian failure in a mouse model via stimulation of the Notch-1 signaling pathway. Exp Ther Med. (2016) 12:21521. doi: 10.3892 /etm.2016.3326

128. Xie Q, Cheng Z, Chen X, Lobe CG, Liu J. The role of Notch signalling in ovarian angiogenesis. J Ovarian Res. (2017) 10:13. doi: 10.1186/s13048-017-0308-5

129. Shutter JR, Scully S, Fan W, Richards WG, Kitajewski J, Deblandre GA, et al. Dll4, a novel Notch ligand expressed in arterial endothelium. Genes Dev. (2000) 14:1313-8. doi: 10.1101/gad.14.11.1313

130. Choi HJ, Armaiz Pena GN, Pradeep S, Cho MS, Coleman RL, Sood AK. Anti-vascular therapies in ovarian cancer: moving beyond anti-VEGF-A approaches. Cancer Metastasis Rev. (2015) 34:19-40. doi: 10.1007/s10555-014-9538-9

131. Hellstrom M, Phng LK, Hofmann JJ, Wallgard E, Coultas L, Lindblom P, et al. Dll4 signalling through Notch1 regulates formation of tip cells during angiogenesis. Nature. (2007) 445:776-80. doi: 10.1038/nature05571

132. Fraser HM, Hastings JM, Allan D, Morris KD, Rudge JS, Wiegand SJ. Inhibition of delta-like ligand 4 induces luteal hypervascularization followed by functional and structural luteolysis in the primate ovary. Endocrinology. (2012) 15:1972-83. doi: 10.1210/en.2011-1688

133. Steg AD, Katre AA, Goodman B, Han HD, Nick AM, Stone RL, et al. Targeting the notch ligand JAGGED1 in both tumor cells and stroma in ovarian cancer. Clin Cancer Res. (2011) 17:5674-85. doi: 10. 1158/1078-0432.CCR-11-0432

134. Patel NS, Li JL, Generali D, Poulsom R, Cranston DW, Harris AL. Upregulation of delta-like 4 ligand in human tumor vasculature and the role of basal expression in endothelial cell function. Cancer Res. (2005) 65:86907. doi: 10.1158/0008-5472-CAN-05-1208

135. Taylor KL, Henderson AM, Hughes CC. Notch activation during endothelial cell network formation in vitro targets the basic HLH transcription factor HESR-1 and downregulates VEGF-AR-2/KDR expression. Microvasc Res. (2002) 64:372-83. doi: 10.1006/mvre.2002.2443

136. Reynolds LP, Grazul-Bilska AT, Redmer DA. Angiogenesis in the female reproductive organs: pathological implications. Int J Exp Pathol. (2002) 83:151-63. doi: 10.1046/j.1365-2613.2002.0 0277.x

137. Corbacho AM, Martínez de la Escalera G, Clapp C. Roles of prolactin and related members of the prolactin/growth hormone/placental lactogen family in angiogenesis. J Endocrinol. (2002) 173:219-328. doi: 10.1677/joe.0.1730219

138. Clapp C, Thebault S, Jeziorski MC, Martínez de la Escalera G. Peptide hormone regulation of angiogenesis. Physiol Rev. (2009) 89:1177215. doi: 10.1152/physrev.00024.2009

Conflict of Interest Statement: The authors declare that the research was conducted in the absence of any commercial or financial relationships that could be construed as a potential conflict of interest.

Copyright (c) 2019 Devesa and Caicedo. This is an open-access article distributed under the terms of the Creative Commons Attribution License (CC BY). The use, distribution or reproduction in other forums is permitted, provided the original author(s) and the copyright owner(s) are credited and that the original publication in this journal is cited, in accordance with accepted academic practice. No use, distribution or reproduction is permitted which does not comply with these terms. 